NASA/TM-2005-213826

\title{
Phased-Array Measurements of Single Flow Hot Jets
}

Sang Soo Lee

QSS Group, Inc., Cleveland, Ohio

James Bridges

Glenn Research Center, Cleveland, Ohio 
Since its founding, NASA has been dedicated to the advancement of aeronautics and space science. The NASA Scientific and Technical Information (STI) Program Office plays a key part in helping NASA maintain this important role.

The NASA STI Program Office is operated by Langley Research Center, the Lead Center for NASA's scientific and technical information. The NASA STI Program Office provides access to the NASA STI Database, the largest collection of aeronautical and space science STI in the world. The Program Office is also NASA's institutional mechanism for disseminating the results of its research and development activities. These results are published by NASA in the NASA STI Report Series, which includes the following report types:

- TECHNICAL PUBLICATION. Reports of completed research or a major significant phase of research that present the results of NASA programs and include extensive data or theoretical analysis. Includes compilations of significant scientific and technical data and information deemed to be of continuing reference value. NASA's counterpart of peerreviewed formal professional papers but has less stringent limitations on manuscript length and extent of graphic presentations.

- TECHNICAL MEMORANDUM. Scientific and technical findings that are preliminary or of specialized interest, e.g., quick release reports, working papers, and bibliographies that contain minimal annotation. Does not contain extensive analysis.

- CONTRACTOR REPORT. Scientific and technical findings by NASA-sponsored contractors and grantees.
- CONFERENCE PUBLICATION. Collected papers from scientific and technical conferences, symposia, seminars, or other meetings sponsored or cosponsored by NASA.

- SPECIAL PUBLICATION. Scientific, technical, or historical information from NASA programs, projects, and missions, often concerned with subjects having substantial public interest.

- TECHNICAL TRANSLATION. Englishlanguage translations of foreign scientific and technical material pertinent to NASA's mission.

Specialized services that complement the STI Program Office's diverse offerings include creating custom thesauri, building customized databases, organizing and publishing research results ... even providing videos.

For more information about the NASA STI Program Office, see the following:

- Access the NASA STI Program Home Page at http://www.sti.nasa.gov

- E-mail your question via the Internet to help@sti.nasa.gov

- Fax your question to the NASA Access Help Desk at 301-621-0134

- Telephone the NASA Access Help Desk at 301-621-0390

- Write to:

NASA Access Help Desk

NASA Center for AeroSpace Information 7121 Standard Drive

Hanover, MD 21076 
NASA/TM-2005-213826

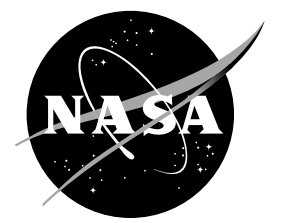

\section{Phased-Array Measurements of Single Flow Hot Jets}

Sang Soo Lee

QSS Group, Inc., Cleveland, Ohio

James Bridges

Glenn Research Center, Cleveland, Ohio

Prepared for the

11th Aeroacoustics Conference

cosponsored by the American Institute of Aeronautics and Astronautics and the Confederation of European Aerospace Societies

Monterey, California, May 23-25, 2005

National Aeronautics and

Space Administration

Glenn Research Center 
Trade names or manufacturers' names are used in this report for identification only. This usage does not constitute an official endorsement, either expressed or implied, by the National Aeronautics and Space Administration.

Available from

NASA Center for Aerospace Information 7121 Standard Drive

Hanover, MD 21076
National Technical Information Service 5285 Port Royal Road Springfield, VA 22100

Available electronically at http:/ /gltrs.grc.nasa.gov 


\title{
Phased-Array Measurements of Single Flow Hot Jets
}

\author{
Sang Soo Lee \\ QSS Group, Inc. \\ Cleveland, Ohio 44135 \\ James Bridges \\ National Aeronautics and Space Administration \\ Glenn Research Center \\ Cleveland, Ohio 44135
}

A 16 microphone phased-array system has been successfully applied to measure jet noise source distributions. In this study, a round convergent nozzle was tested at various hot and cold flow conditions: acoustic Mach numbers are between 0.35 and 1.6 and static temperature ratios are varied from cold to 2.7. The classical beamforming method was applied on narrowband frequencies. From the measured source distributions locations of peak strength were tracked and found to be very consistent between adjacent narrowband frequencies. In low speed heated and unheated jets, the peak source locations vary smoothly from the nozzle exit to downstream as the frequency is decreased. When the static temperature ratio was kept constant, the peak source position moved downstream with increasing acoustic Mach number for the Strouhal numbers smaller than about 1.5. It was also noted that the peak source locations of low frequencies occur farther downstream than the end of potential core.

\section{Introduction}

This report presents the results of a recent phased-array test sponsored by the NASA Quiet Aircraft Technology program. This test was conducted on the Small Hot Jet Acoustic Rig (SHJAR) at the NASA Glenn Research Center.

It is important to know the noise source locations of a jet flow in order to develop successful jet noise prediction methods. Many techniques that can find the frequency dependent source locations along the jet direction have been published. Among these techniques are: the acoustic mirror method (refs. 1 and 2), the cross-correlation technique (ref. 3), the polar correlation method (ref. 4), the two microphone minimum phase method (ref. 5), and the phased-array beamforming method (refs. 6, 7, 14, and 15). The phased array beamforming methods are summarized in detail by Dougherty (ref. 8) and Underbrink (ref. 9). Some of these methods can only find a single 'source location' for a given frequency band, while phased arrays produce maps of source strength, convolved with the point spread function of the array.

As a part of the NASA jet noise database program (refs. 10 through 12) that includes detailed flow and acoustic measurements, the one-dimensional phased-array system is used to determine the jet noise source locations. The linear array is composed of 16 microphones positioned on the floor at unequal intervals. A simple round convergent nozzle was tested at various acoustic Mach numbers from 0.35 to 1.6 and static temperature ratios from cold to 2.7. Classical beamforming methods have been used in the image processing.

In the following sections, we will show the array patterns of the linear array and the noise source locations of heated and cold jets. The effects of acoustic Mach numbers and of static temperature ratios on the noise source locations will also be discussed.

\section{Test Hardware, Linear Array and Data Processing}

The Small Hot Jet Acoustic Rig (SHJAR) at the NASA Glenn Research Center is a single stream jet rig with a hydrogen combustor. The maximum Mach number is about 2 and the maximum static temperature ratio is about 2.8. The centerline of the jet is 10 feet above the floor. The SHJAR is located within the Aeroacoustic Propulsion Laboratory (AAPL). The AAPL is a 65 foot radius anechoic hemispherical dome with its interior covered by sound absorbent wedges. More details on the test facility can be found in the papers by Bridges and Brown (ref. 10 and 11) and Bridges and Wernet (ref. 12). 
A simple round convergent nozzle is used for the test. The diameter of the NASA baseline nozzle, SMC000, is 2 inches. A drawing and a picture of the nozzle can be found in Bridges and Brown (refs. 10 and 11).

Test data was acquired on a subset of flow conditions defined by Tanna (ref. 13) for hot jets as a part of the NASA jet noise database (refs. 10 through 12). The acoustic Mach numbers are varied within the range between 0.35 and 1.6 and the static temperature ratios are varied up to 2.7. Figure 1 shows the flow conditions where the phased-array data are obtained.

The linear phased-array system was composed of 16 microphones positioned at unequal intervals. The phased-array was installed on the floor in parallel with the jet-flow centerline. The array was located 49.875 inches off to the side. The microphones were flush mounted without the protective grids. The microphone positions in the array are shown in figure 2. The origin of the right-handed Cartesian coordinate system is located at the center of the nozzle exit plane. The $\mathrm{x}$ coordinate is on the jet centerline with positive values in the jet-flow downstream direction. The $\mathrm{x}$ and $\mathrm{y}$ coordinates are parallel with and the $\mathrm{z}$ coordinate is perpendicular to the floor. The microphone coordinates are given in table 1 along with the radial distance between each microphone and the center of the nozzle exit plane and the direction angle for the radius of each microphone measured relative to the negative $\mathrm{x}$ axis.

The 1/4 inch microphones are used to measure sound pressure levels. The microphone preamplifiers are connected to the four-channel microphone conditioning amplifier, B\&K Nexus 2690 unit. The outputs of the Nexus 2690 are connected into the Datamax data acquisition system. The sampling rate of the Datamax system was $200 \mathrm{KHz}$ with the bandwidth of $90 \mathrm{KHz}$. All 16 microphone signals are recorded simultaneously for more than 10 seconds. The calibration constant for each microphone is obtained by using a $250 \mathrm{~Hz}$ pistonphone. The phase corrections of microphones are not applied to the measured data. The 'as measured' signals are used to compute the narrowband spectra and the beamforming outputs presented in this paper.

For the cross-spectral density calculations, the Matlab function 'csd' was used with 8192 data points, 50 percent overlapping and Hanning's periodic window. All beamforming analyses have been performed based on the narrowband cross-spectral densities with bandwidth of $24.41 \mathrm{~Hz}$. The classical beamforming method described in Dougherty (ref. 6) has been used in the image processing. The jet noise directivity was not accounted for in the beamforming process. The directivity, thus, can be considered as a microphone weighting factor. Any other microphone weighing factor was not used in the beamforming process. The effect of refraction was also ignored since it is expected to introduce relatively small errors in the source location estimate (refs. 14 and 15). The distribution of source strength estimates produced by the beamforming process is referred to as source levels.

\section{Array Pattern and Point Sound Source Response}

The array pattern of the linear phased array for a source located at $\mathrm{x} / \mathrm{D}=2$, where $\mathrm{D}$ represents the nozzle diameter of 2 inches, is given in figure 3. The array patterns at all narrowband frequencies are computed and their contour plot is plotted on the left side with the color bar of a $20 \mathrm{~dB}$ scale. The peak locations and -1 and $-3 \mathrm{~dB}$ contour lines of the array patterns are plotted on the right side. The peak locations and $-1 \mathrm{~dB}$ contour lines of the array patterns when a single source is located at $\mathrm{x} / \mathrm{D}=0,5,10$ or 15 are given in figure 4 . Since the center of the phased array is located about 20 diameters from the nozzle exit, the low frequency peak locations of the array pattern incorrectly appear at more upstream positions than the source locations. This is more apparent to the sources located closer to the nozzle exit. However, this effect becomes less critical in jet flows because the low frequency source locations usually occur at downstream locations.

The measured source distribution of an acoustic sound source are given in figure 5. The bottom end of a 10 foot long steel pipe of one inch diameter is connected to an acoustic driver on the floor and the top end is positioned about 3.85 nozzle diameters from the nozzle exit on the jet centerline. The acoustic driver is fed by an amplifier with a white noise generator. The classical beamforming method is used to calculate the source strength levels along the jet centerline for all narrowband frequencies. At each frequency the location of the peak strength and its level, given in the first two columns in the second row in figure 5, are found from the streamwise location where the maximum source level occurs. The contour plots of source strength levels are given in the top row. The source levels, normalized by the peak level at each frequency, are used in the upperleft contour plot with $20 \mathrm{~dB}$ color bar scale. Meanwhile, the contour plot of the absolute source levels is shown in the upper-right figure with the color bar in $\mathrm{dB}$ scale. The narrowband spectra for all 16 microphones are plotted in the bottom-right figures. The microphone numbers are given with the colors of lines in parentheses where $\mathrm{k}, \mathrm{b}, \mathrm{g}$, and $\mathrm{r}$ correspond to black, blue, green, and red. Those of the back ground noise are plotted with dotted curves for comparison. 
This linear array is shown to successfully find the acoustic source locations for all frequencies where the acoustic source is stronger than the background noise level. The narrowband spectra in the bottom-right figures show that the acoustic device generates effective noise between $500 \mathrm{~Hz}$ and $10 \mathrm{KHz}$.

In figure 6 , the beamforming results obtained for the acoustic sound source at two different locations, $\mathrm{x} / \mathrm{D}=1.5$ and 3.85 , are compared against corresponding array patterns. The peak locations from the measurements of source distribution are plotted with blue dots along with the -1 and $-3 \mathrm{~dB}$ contour lines plotted with green and cyan curves, respectively. Those from the array patterns are plotted with black dots and red and magenta curves, respectively. Within the frequency range of between $500 \mathrm{~Hz}$ and $10 \mathrm{KHz}$ where the acoustic driver sound level is higher than the background level, the beamforming results agree very well with the array patterns. The zigzag behavior in the beamforming results from the acoustic sources indicates that the source locations are varied within the exit pipe plane whose diameter is $0.5 \mathrm{D}$.

\section{Results}

\section{A. Heated Jets}

Figure 7 shows the beamforming results for a heated jet at set point 44 . The acoustic Mach number $\mathrm{M}_{\mathrm{a}}\left(=\mathrm{V}_{\mathrm{J}} / \mathrm{c}_{\mathrm{o}}\right)$, where $\mathrm{V}_{\mathrm{J}}$ is the jet exit velocity and $\mathrm{c}_{\mathrm{o}}$ is the ambient speed of sound, is 0.689 and the static temperature ratio, $\mathrm{Ts}_{\mathrm{J}} / \mathrm{T}_{\mathrm{a}}$ is 2.712 . The source strength levels along the jet centerline are computed by using classical beamforming methods given in Dougherty (ref. 6). The peak locations and peak levels are found from the streamwise locations where the maximum source level occurs. The $-1 \mathrm{~dB}$ contour lines from the normalized source levels are plotted with green curves and the $-3 \mathrm{~dB}$ contour lines from the absolute source levels are plotted with magenta curves in the bottom-left figure. The contour plots of the source levels normalized by their peak levels and those of the absolute source levels are given in the top figures. The narrowband spectra for all 16 microphones are plotted in the bottom-right figures.

As shown in the bottom-left figure, the peak locations of the source levels gradually move from downstream positions to the nozzle exit as the frequency is increased. However, it is interesting to observe that the peak locations at adjacent frequencies are distributed within narrow streamwise sections of about 0.8 jet diameters. This may indicate that the noise sources at a given frequency are distributed in this narrow streamwise section.

For very high frequencies when the Strouhal numbers, $S t\left(=\mathrm{fD} / \mathrm{V}_{\mathrm{J}}\right)$, are greater than 8 , the peak locations occur at the nozzle exit, $x / D=0$, although their peak levels are relatively low. The $-3 \mathrm{~dB}$ contour line of the absolute source levels and the peak levels, given in the first two bottom figures, show that the peak levels are high when the Strouhal numbers are between 0.1 and 0.4 . The peak locations at these frequencies occur at about 4 to 7 diameters from the nozzle exit that corresponds to the end of potential core.

Figure 8 shows the beamforming results at the set point 141 when the acoustic Mach number $\left(\mathrm{V}_{\mathrm{J}} / \mathrm{c}_{\mathrm{o}}\right)$ is 1.578 and the static temperature ratio $\left(\mathrm{Ts}_{\mathrm{j}} / \mathrm{T}_{\mathrm{a}}\right)$ is 2.707 .

The comparison of the peak locations is shown in figure 9(a) with black dots for the higher speed set point 141 and with blue dots for the lower speed set point 44 . The peak locations of both set points follow nearly the same trend when the Strouhal numbers are higher than about 1.5. The peak locations of the higher speed set point are distributed in wider streamwise sections compared to the lower speed case.

However, the peak locations of the higher speed jet occur at farther downstream streamwise locations than those of the lower speed jet when the Strouhal numbers are lower than about 1.5. This may indicate that the low frequency noise generated near the end of potential core region is dependent on the length of the potential core but the high frequency noise generated in the initial shear layer is only dependent on the nozzle geometry. The measured centerline decay of the mean velocity by Bridges and Wernet (ref. 12) shows that higher acoustic Mach number makes the potential core length longer when the static temperature ratio is kept constant.

Another noticeable difference between these two cases occurs at the Strouhal numbers between 0.2 and 0.5. The peak locations of the set point 44 gradually move downstream as the frequency is decreased. Meanwhile, those of the set point 141 occur almost at the same streamwise locations of about 6 to 7.5 diameters. The same behavior has been found in the peak locations of the other heated jets we have tested.

The effects of acoustic Mach number on the peak locations of source levels are shown in figures 9 to 12 when the static temperature ratios are 2.7, 2.27, 1.765, and 1.429, respectively. The peak locations of low speed jets, i.e., when the acoustic Mach number is about 0.7 , are more compactly distributed in the streamwise direction compared to those of higher speed jets. The peak locations at high Strouhal numbers are independent of the acoustic Mach number. However, when the Strouhal numbers are smaller than about 1.5, the peak locations move toward downstream positions as the acoustic Mach number is increased. The most noticeable 
effect of the acoustic Mach number occurs at the Strouhal numbers between 0.2 and 0.8 . When the static temperature ratio is small, the difference of the peak locations between high and low speed jets becomes smaller since the maximum acoustic Mach number we can obtain before the jet becomes sonic is lower. In all temperature ratio cases, the peak locations of very low frequencies appear at very far downstream positions, especially for the high speed jets.

The effects of the static temperature ratio on the peak locations are given in figures 13 to 18 for the acoustic Mach numbers of $0.7,0.9,1,1.185,1.33$, and 1.48, respectively. The peak locations of high Strouhal numbers, larger than 0.6 or 0.8 , are independent of the static temperature ratio. However, the peak locations of lower Strouhal numbers move toward upstream positions as the static temperature ratio is increased. When the Strouhal number is 0.2 , the peak location of the highest temperature ratio jet $\left(\mathrm{Ts}_{\mathrm{J}} / \mathrm{T}_{\mathrm{a}}=2.7\right)$ occurs at about 2 jet diameters upstream positions than the lowest one $\left(\mathrm{Ts}_{\mathrm{J}} / \mathrm{T}_{\mathrm{a}}=1.429\right)$ for all cases shown in figures 13 to 16 .

\section{B. Cold Jets}

Figures 19 and 20 show the beamforming results for cold jets at the set points 3 and 7 . The acoustic Mach numbers $\left(\mathrm{V}_{\mathrm{J}} / \mathrm{c}_{\mathrm{o}}\right)$ are 0.491 and 0.891 and the static temperature ratios $\left(\mathrm{Ts}_{\mathrm{J}} / \mathrm{T}_{\mathrm{a}}\right)$ are 0.967 and 0.84 , respectively. The peak locations of the beamforming levels are changed from downstream positions to the nozzle exit as the frequency is increased. Similar to the heated jet cases given in figures 7 and 8 , the peak locations of lower speed jets are more closely distributed along the jet centerline compared to the higher speed jets.

The effect of acoustic Mach number on peak source location is shown in figure 21 when the acoustic Mach number is varied from 0.34 to 0.9 . The locations of peak source strength for higher speed jets occurs at farther downstream locations than those of the lower speed jets for Strouhal numbers lower than about 1.5. In addition, the peak location of low frequencies occur at farther downstream locations than the end of potential core.

\section{Comparison With Other Techniques}

\section{A. Cold Jets}

Figure 22 shows the comparison with other source location techniques. The locus of peak source strength from the current phased array method at the set point $7\left(\mathrm{M}_{\mathrm{J}}=0.972, \mathrm{Ts}_{\mathrm{J}} / \mathrm{T}_{\mathrm{a}}=0.84, \mathrm{D}=25.4 \mathrm{~mm}\right)$ are plotted with green dots. The results from the acoustic mirror method by Chu, et al. (ref. 1) $\left(\mathrm{M}_{\mathrm{J}}=1, \mathrm{D}=25.4 \mathrm{~mm}\right)$ are given with blue squares and those by Grosche (ref. 2) $\left(\mathrm{M}_{\mathrm{J}}=1, \mathrm{D}=20 \mathrm{~mm}\right)$ are given with blue circles. The peak locations from the polar correlation techniques by Fisher, et al. (ref. 4) are plotted with black down triangles $\left(\mathrm{M}_{\mathrm{J}}=0.86, \mathrm{D}=25.4 \mathrm{~mm}\right)$ and up triangles $\left(\mathrm{M}_{\mathrm{J}}=0.86, \mathrm{D}=50.8 \mathrm{~mm}\right)$. The results from the two microphone minimum phase method by Ahuja, et al. (ref. 5) are plotted with red $+\left(\mathrm{M}_{\mathrm{J}}=0.89, \mathrm{D}=25.4 \mathrm{~mm}\right)$, $\mathrm{x}\left(\mathrm{M}_{\mathrm{J}}=0.89, \mathrm{D}=50.8 \mathrm{~mm}\right)$, and $*\left(\mathrm{M}_{\mathrm{J}}=0.89, \mathrm{D}=61 \mathrm{~mm}\right)$. This shows that peak locations determined by using different techniques at different facilities agree relatively well with each other.

It was also shown in Venkatesh, et al. (ref. 14) that the noise source distribution centroids are in better agreement with the source locations obtained by the other techniques presented in figure 22 . Their phased array analysis with distributed source beamforming algorithm showed that the streamwise centroid positions of the jet noise source distribution occur at later downstream positions than the peak source locations, especially at high frequencies. For example, the noise source distribution centroid at the Strouhal number of 5.31 occurs at about 1.8 jet diameters downstream than the source peak location.

In figure 23 , the peak source locations from current analysis at the set points $4\left(\mathrm{M}_{\mathrm{J}}=0.615, \mathrm{Ts}_{\mathrm{J}} / \mathrm{T}_{\mathrm{a}}=0.941\right)$, $5\left(\mathrm{M}_{\mathrm{J}}=0.73, \mathrm{Ts}_{\mathrm{J}} / \mathrm{T}_{\mathrm{a}}=0.91\right)$, and $6\left(\mathrm{M}_{\mathrm{J}}=0.849, \mathrm{Ts}_{\mathrm{J}} / \mathrm{T}_{\mathrm{a}}=0.878\right)$ are plotted with cyan, yellow and green dots, respectively. The peak noise source locations of cold jets obtained by Narayanan, et al. (ref. 15) are plotted with open red symbols for the jet Mach numbers of 0.6 (square), 0.7 (circle), and 0.9 (triangle). Their jet diameter was $82.27 \mathrm{~mm}$ and the jet exit temperature was $80^{\circ} \mathrm{F}$. Narayanan, et al. (ref. 15) used the delay-and-sum beamforming algorithm with optimum sensor weighting to process the data from the 36 microphone linear phased array system. Figure 23 shows that the peak source locations obtained by the phased array methods from both tests are in good agreement.

\section{B. Hot Jets}

The comparison of the peak source locations of heated jets is given in figure 24. Those from current test at the set points $137\left(\mathrm{M}_{\mathrm{J}}=0.613, \mathrm{Ts}_{\mathrm{J}} / \mathrm{T}_{\mathrm{a}}=2.695\right)$, and $150\left(\mathrm{M}_{\mathrm{J}}=0.887, \mathrm{Ts}_{\mathrm{J}} / \mathrm{T}_{\mathrm{a}}=2.718\right)$ are plotted with yellow and green dots, respectively. The peak source locations by Narayanan, et al. (ref. 15) are plotted with open red symbols when the jet Mach numbers are 0.6 (square), and 0.9 (circle). The jet exit temperatures are $1000^{\circ} \mathrm{F}$ for 
both conditions. The peak source locations obtained by current phased array method occur at upstream positions than those by Narayanan, et al. (ref. 15). However, the peak noise locations of the high speed jet occur at farther downstream locations compared with the low speed jet in both phased array analyses.

\section{Concluding Remarks}

The phased-array system has been successfully applied to measure the distribution of jet noise source strength in hot and cold single-flow jets. It was shown that the 16 microphone linear phased-array system installed on the floor parallel to the jet-flow centerline was able to detect correct acoustic source locations for known acoustic sources. A round convergent nozzle of 2 inch diameter was then used in a series of tests as a part of the NASA jet noise database. The acoustic Mach numbers are varied from 0.35 to 1.6 and the static temperature ratios are varied from cold to 2.7. The classical beamforming analyses have been performed based on the narrowband cross-spectral densities with bandwidth of $24.41 \mathrm{~Hz}$.

The measured locations of peak source strength in low speed heated jets at adjacent frequencies are distributed within a very narrow band of streamwise sections while those of higher speed heated jets are distributed over a wider streamwise extent. The peak source strength at high Strouhal numbers is independent of the acoustic Mach number. However, when the Strouhal numbers are smaller than about 1.5, the locations of the peak for constant static temperature ratio jets moves downstream as the acoustic Mach number is increased. The locus of source peaks at lower Strouhal numbers moves upstream as the static temperature ratio is increased when the acoustic Mach number is kept constant.

The locus of peak source strength for cold jets is in good agreement with other reported source location techniques, including the acoustic mirror, polar correlation and two microphone minimum phase methods. The source locations are gradually varying from the nozzle exit to the downstream positions as the frequencies decrease. The peak locations of low frequencies occur at farther downstream locations than the end of potential core.

\section{References}

1. Chu, W.T., Laufer, J., and Kao, K., "Noise Source Distribution in Subsonic Jets," International Conference on Noise Control, Washington D.C., 1972.

2. Grosche, F.R., "Distributions of Sound Source Intensities in Subsonic and Supersonic Jets," CP-31, AGARD Paper 4, 1973.

3. Billingsley, J. and Kinns, R., "The Acoustic Telescope," Journal of Sound and Vibration, vol. 48, 1976, pp. 485-510.

4. Fisher, M.J., Harper-Bourne, M., and Glegg, S.A.L., "Jet Engine Noise Source Location: the Polar Correlation Technique," Journal of Sound and Vibration, vol. 51, 1977, pp. 23-54.

5. Ahuja, K.K., Massey, K.C., and D'Agostino, M.S., "A Simple Technique of Locating Noise Source of a Jet Under Simulated Forward Motion," AIAA-98-2359, 1998.

6. Dougherty, R.P., "Phased Array Beamforming for Aeroacoustics," AIAA Professional Development Short Course, 8-9 May 1999.

7. Mosher, M., "Phased Arrays for Aeroacoustic Testing: Theoretical Development," AIAA-96-1713, 1996.

8. Dougherty, R.P., "Beamforming in Acoustic Testing," in Aeroacoustic Measurements, Mueller, T.J. (ed.), 2002.

9. Underbrink, J.R., "Aeroacoustic Phased Array Testing in Low Speed Wind Tunnels," in Aeroacoustic Measurements, Mueller, T.J. (ed.), 2002.

10. Bridges, J. and Brown, C.A., "Validation of the Small Hot Jet Acoustic Rig for Aeroacoustic Research," AIAA-2005-2846.

11. Bridges, J. and Brown, C.A., "Parametric Testing of Chevrons on Single Flow Hot Jets," AIAA-20042824.

12. Bridges, J. and Wernet, M.P., Measurements of the Aeroacoustic Sound Sources in Hot Jets, AIAA-20033130 .

13. Tanna, H.K., "The Influence of Temperature on Shock-free Supersonic Jet Noise," J. Sound Vibration, vol. 39, 1975.

14. Venkatesh, S.R., Polak, E.R., and Narayanan, S., "Beamforming Algorithm for Distributed Source Location and Its Application to Jet Noise," AIAA Journal, vol. 41, pp. 1238-1246, 2003.

15. Narayanan, S., Barber, T.J., and Polak, D.R. "High Subsonic Jet Experiments: Turbulence and Noise Generation Studies," AIAA Journal, vol. 40, pp. 430-437, 2002. 
TABLE 1.-MICROPHONE COORDINATES OF THE LINEAR PHASED-ARRAY SYSTEM

\begin{tabular}{|c|c|c|c|c|c|}
\hline mic no & $\mathbf{x}$ (in) & $\mathbf{y}$ (in) & $\mathbf{z}$ (in) & $\mathbf{r}$ (in) & angle (deg) \\
\hline 1 & -9.43 & 49.875 & -113.75 & 124.56 & 85.66 \\
\hline 2 & 2.11 & 49.875 & -113.75 & 124.22 & 90.97 \\
\hline 3 & 12.07 & 49.875 & -113.75 & 124.79 & 95.55 \\
\hline 4 & 20.63 & 49.875 & -113.75 & 125.91 & 99.43 \\
\hline 5 & 27.96 & 49.875 & -113.75 & 127.31 & 102.69 \\
\hline 6 & 34.19 & 49.875 & -113.75 & 128.82 & 105.39 \\
\hline 7 & 39.47 & 49.875 & -113.75 & 130.32 & 107.63 \\
\hline 8 & 43.91 & 49.875 & -113.75 & 131.74 & 109.47 \\
\hline 9 & 48.35 & 49.875 & -113.75 & 133.28 & 111.27 \\
\hline 10 & 53.63 & 49.875 & -113.75 & 135.29 & 113.35 \\
\hline 11 & 59.86 & 49.875 & -113.75 & 137.88 & 115.73 \\
\hline 12 & 67.19 & 49.875 & -113.75 & 141.21 & 118.41 \\
\hline 13 & 75.75 & 49.875 & -113.75 & 145.48 & 121.38 \\
\hline 14 & 85.71 & 49.875 & -113.75 & 150.91 & 124.61 \\
\hline 15 & 97.25 & 49.875 & -113.75 & 157.75 & 128.06 \\
\hline 16 & 110.57 & 49.875 & -113.75 & 166.29 & 131.68 \\
\hline
\end{tabular}

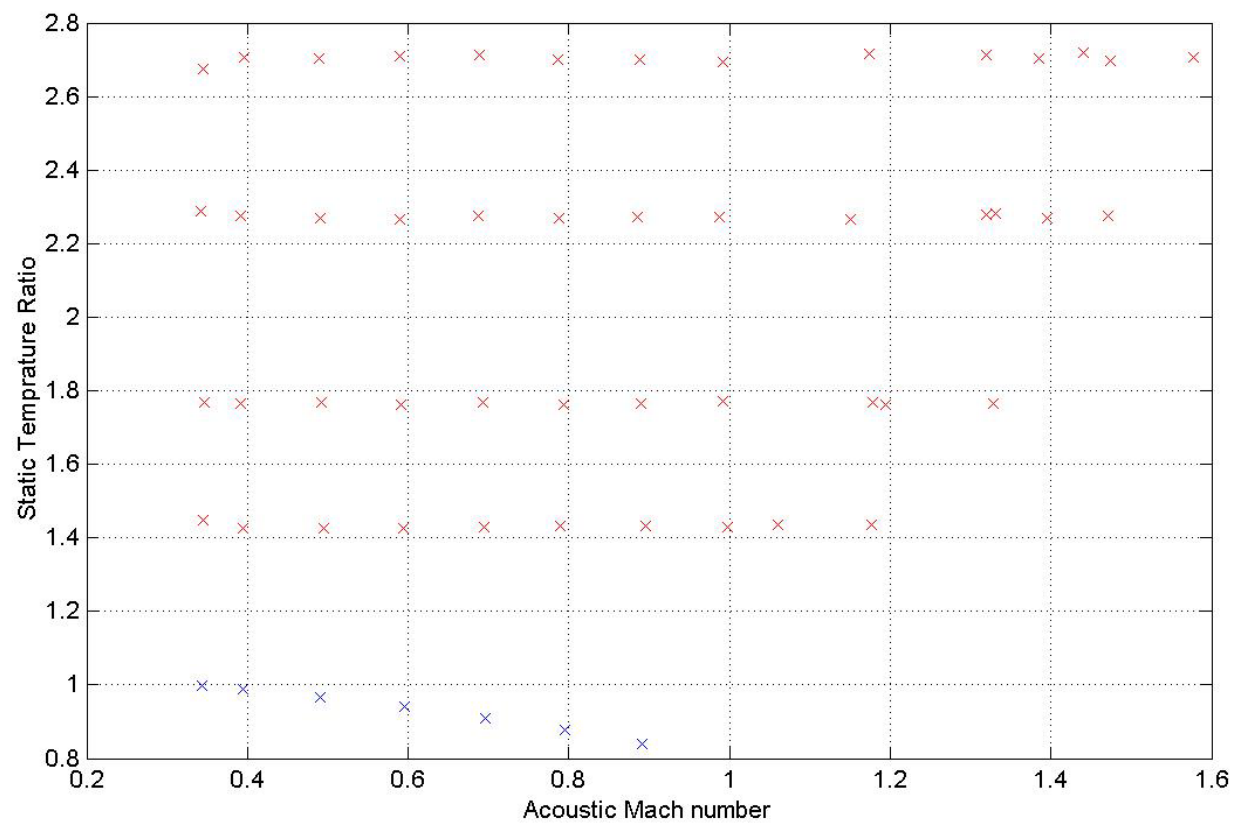

Figure 1.-Test flow conditions. $\mathrm{Ts}_{\mathrm{J}} / \mathrm{T}_{\mathrm{a}} \mathrm{vs} . \mathrm{M}_{\mathrm{a}}\left(=\mathrm{V}_{\mathrm{J}} / \mathrm{c}_{\mathrm{o}}\right)$.

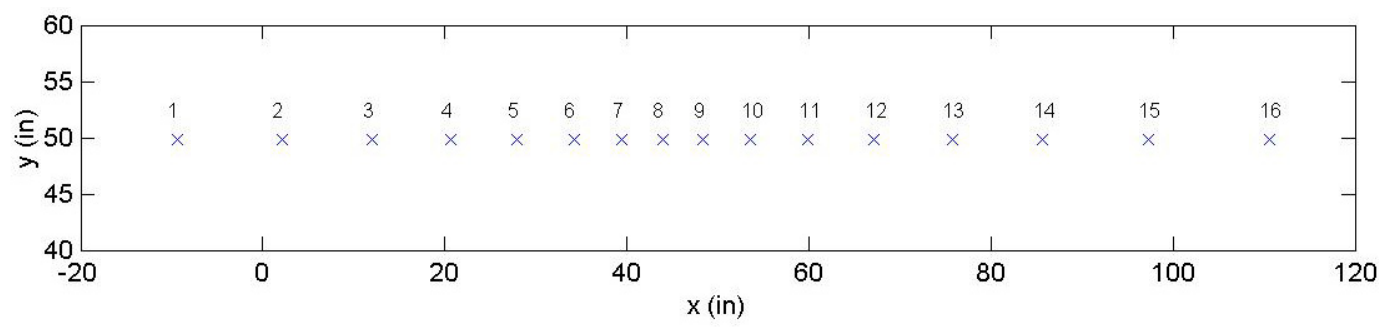

Figure 2.-Microphone positions of the linear phased-array system. 

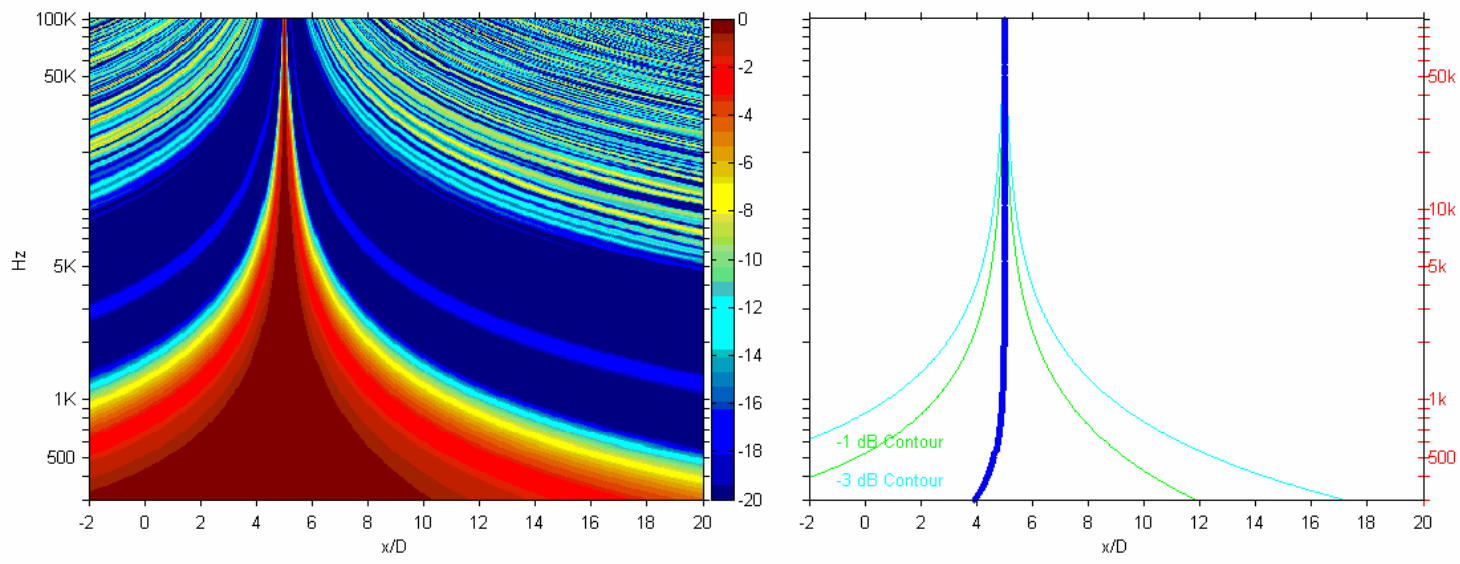

Figure 3.-Array pattern with a source located at $\mathrm{x} / \mathrm{D}=5$.

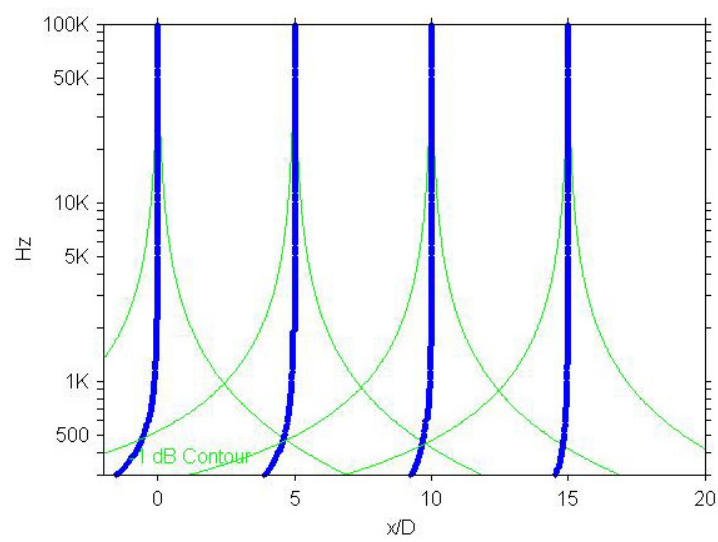

Figure 4.-Peak locations and $-1 \mathrm{~dB}$ contour lines of array patterns with a single source at $\mathrm{x} / \mathrm{D}=0,5,10$ or 15 . 


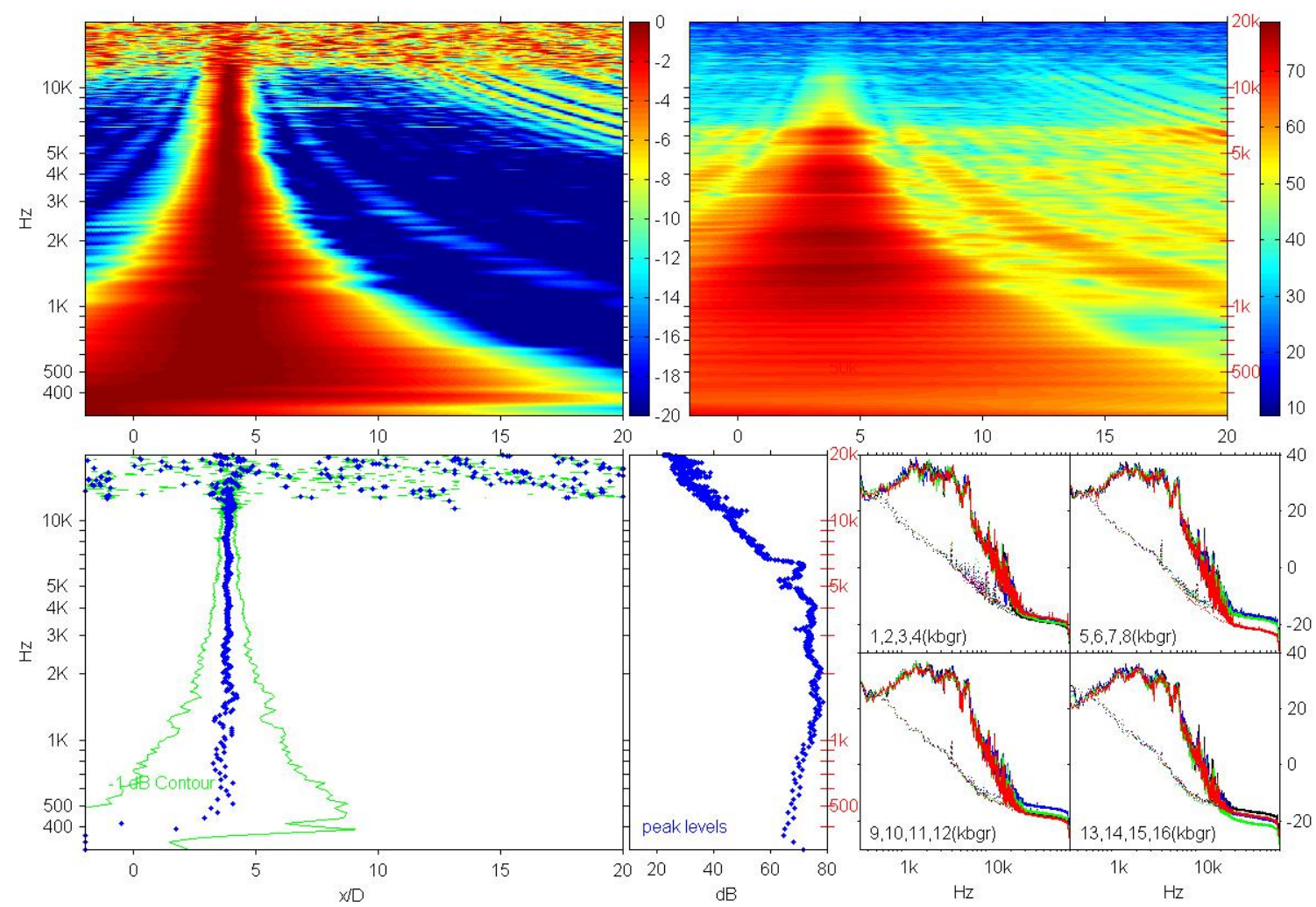

Figure 5.-Classical beamforming results of an acoustic sound source at $\mathrm{x} / \mathrm{D}=3.85$.
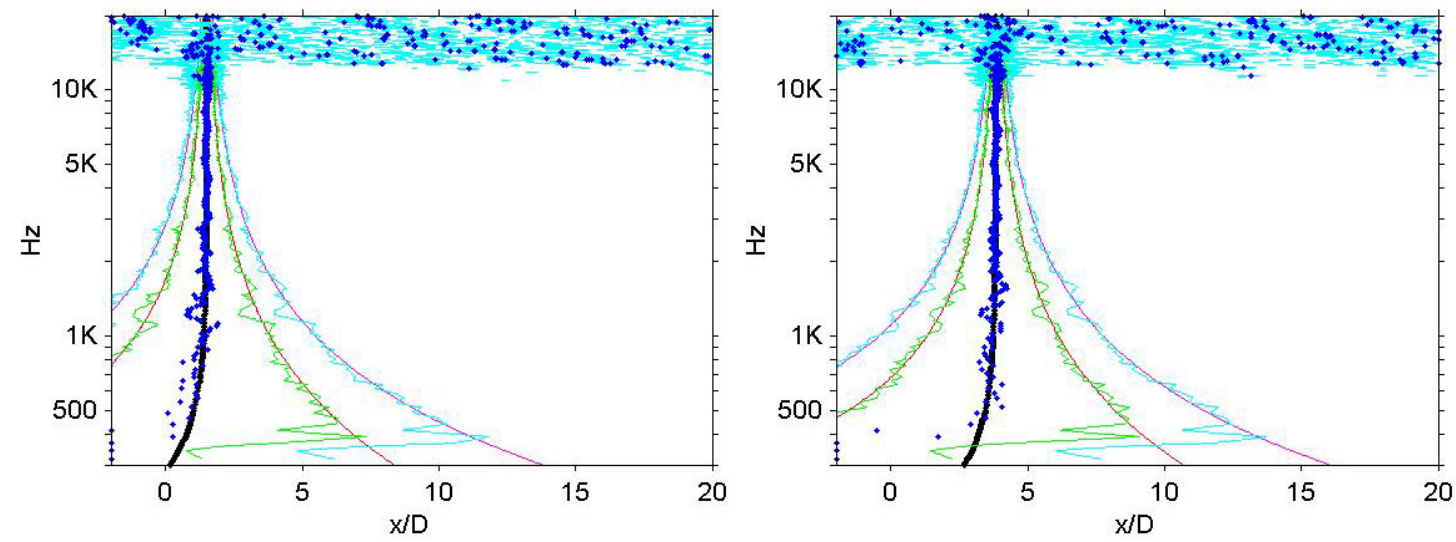

Figure 6.-Comparisons of peak locations and -1 and $-3 \mathrm{~dB}$ contour lines between acoustic source beamforming and array pattern with a sound source at $\mathrm{x} / \mathrm{D}=1.5$ (left) and 3.85 (right). 


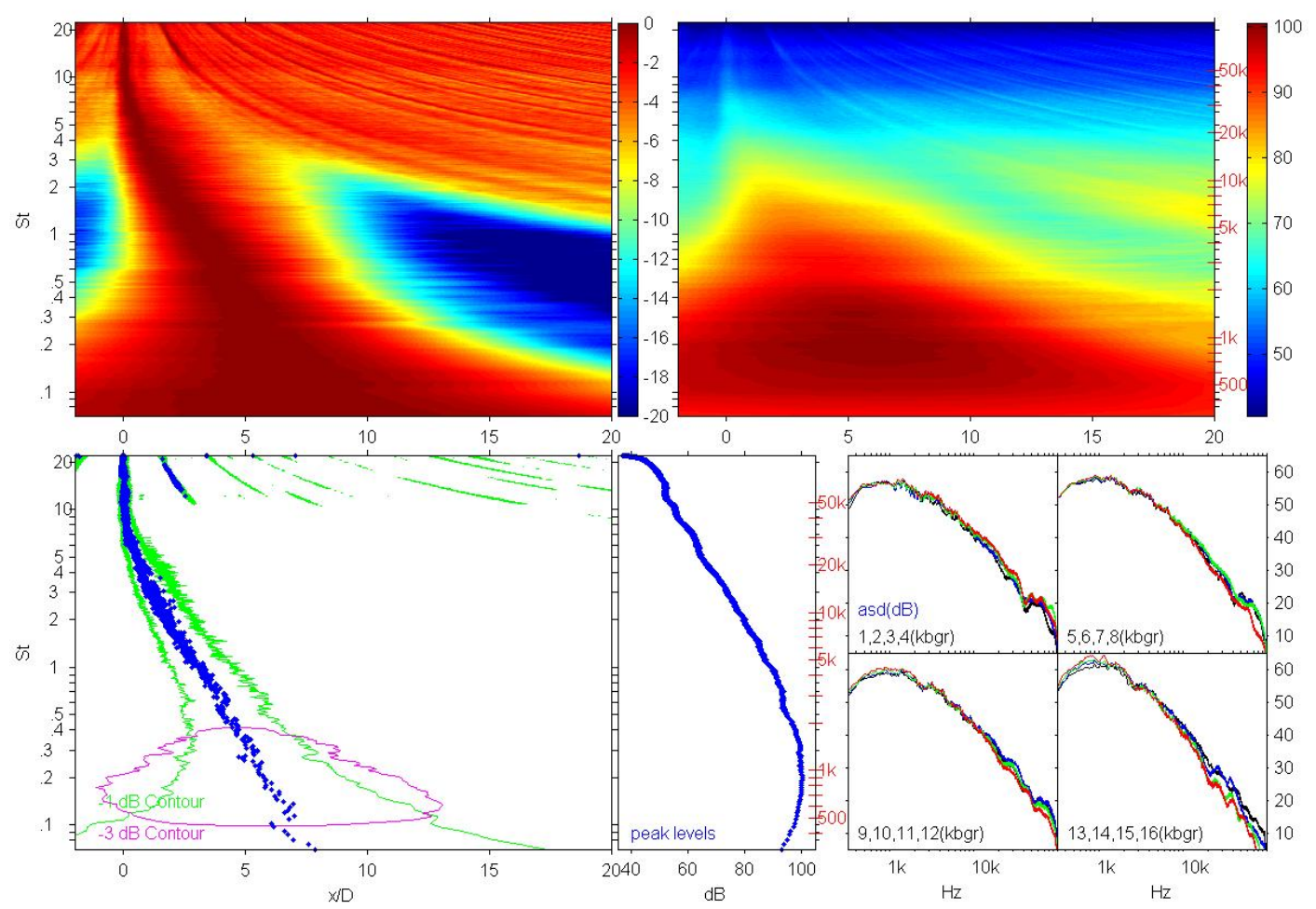

Figure 7.-Beamforming results of a heated jet at the set point $44: \mathrm{M}_{\mathrm{a}}=0.689$ and $\mathrm{Ts}_{\mathrm{J}} / \mathrm{T}_{\mathrm{a}}=2.712$.

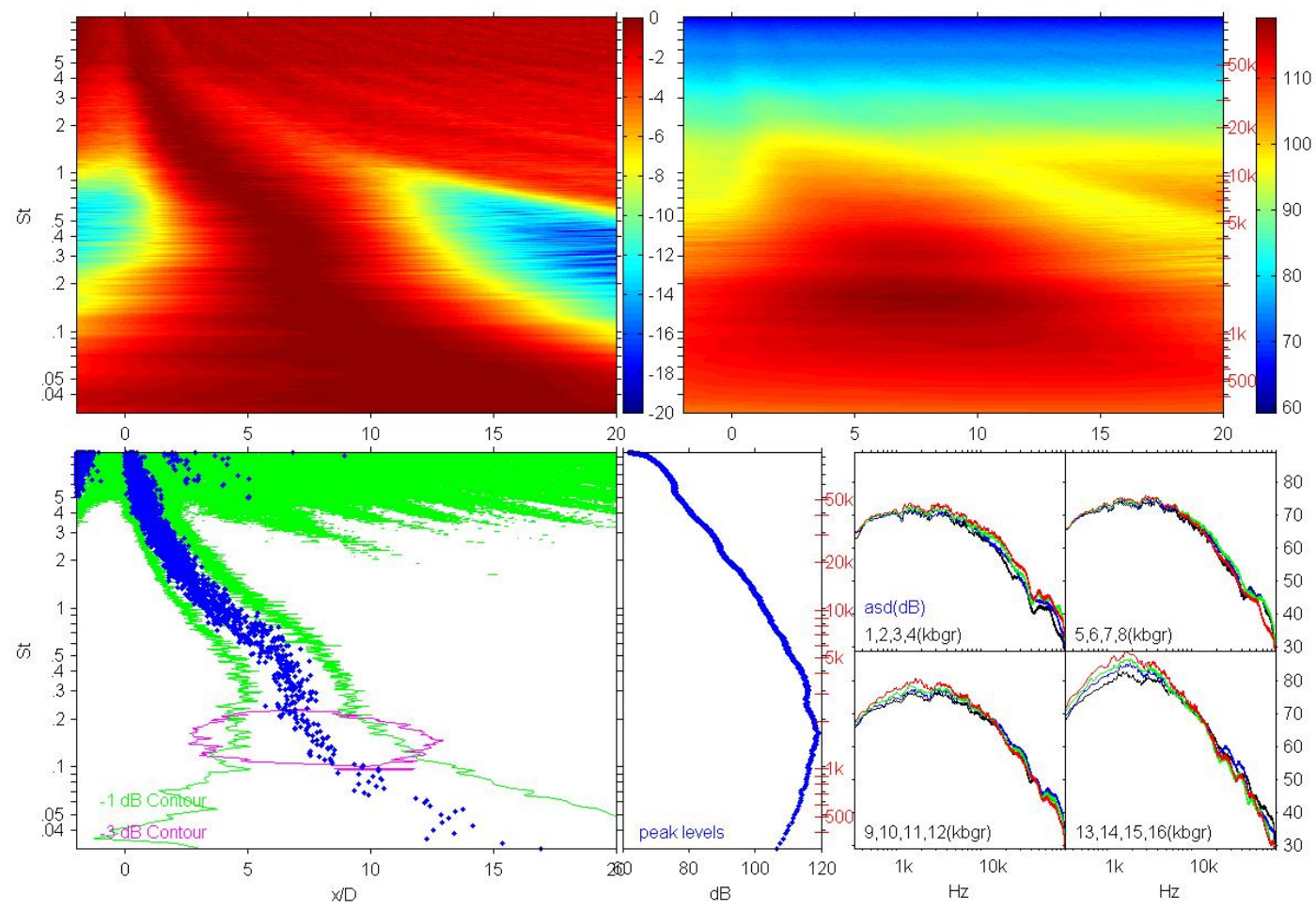

Figure 8.-Beamforming results of a heated jet at the set point $141: \mathrm{M}_{\mathrm{a}}=1.578$ and $\mathrm{Ts}_{\mathrm{J}} / \mathrm{T}_{\mathrm{a}}=2.707$. 

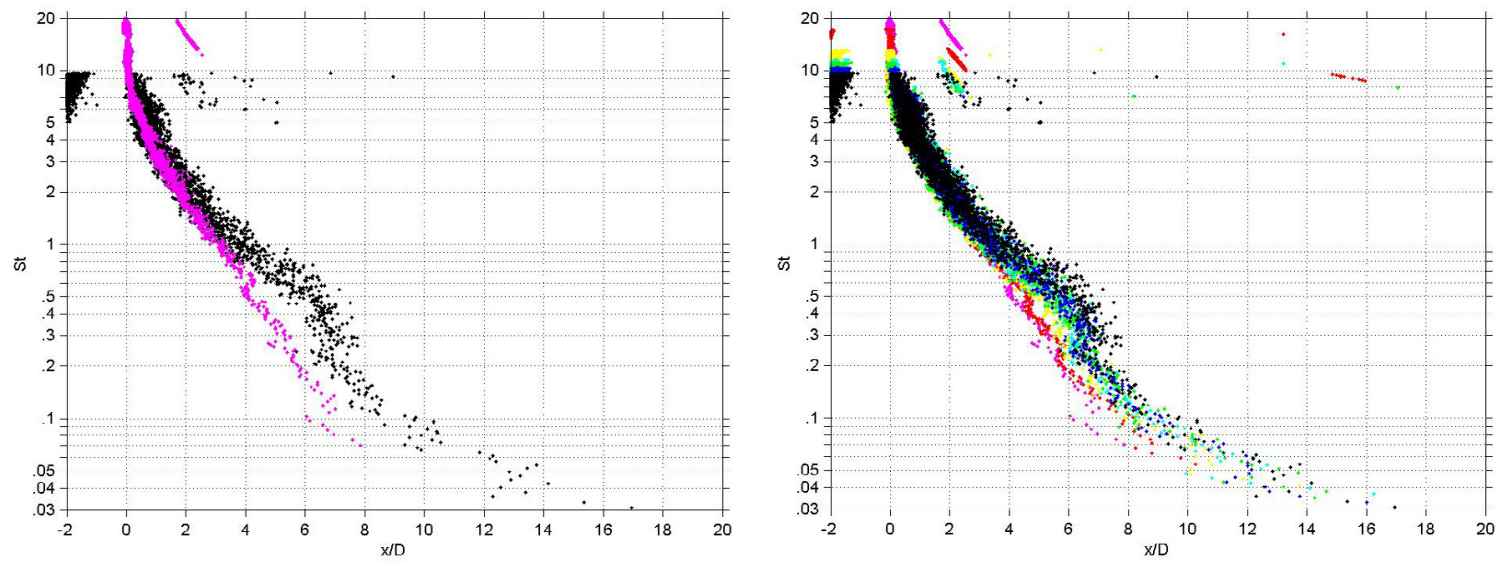

Figure 9.-Effect of acoustic Mach number on the peak locations of beamforming levels when the static temperature ratio is 2.7: (setpoint, $\mathrm{M}_{\mathrm{a}}, \mathrm{Ts}_{\mathrm{J}} / \mathrm{T}_{\mathrm{a}}$, color $)=(44,0.689,2.712$, magenta), $(46,0.888,2.699$, red), (47, 1.174, 2.715, yellow), (48, 1.32, 2.714, cyan), (140, 1.385, 2.703, green), (49, 1.474, 2.696, blue), and $(141,1.578,2.707$, black).
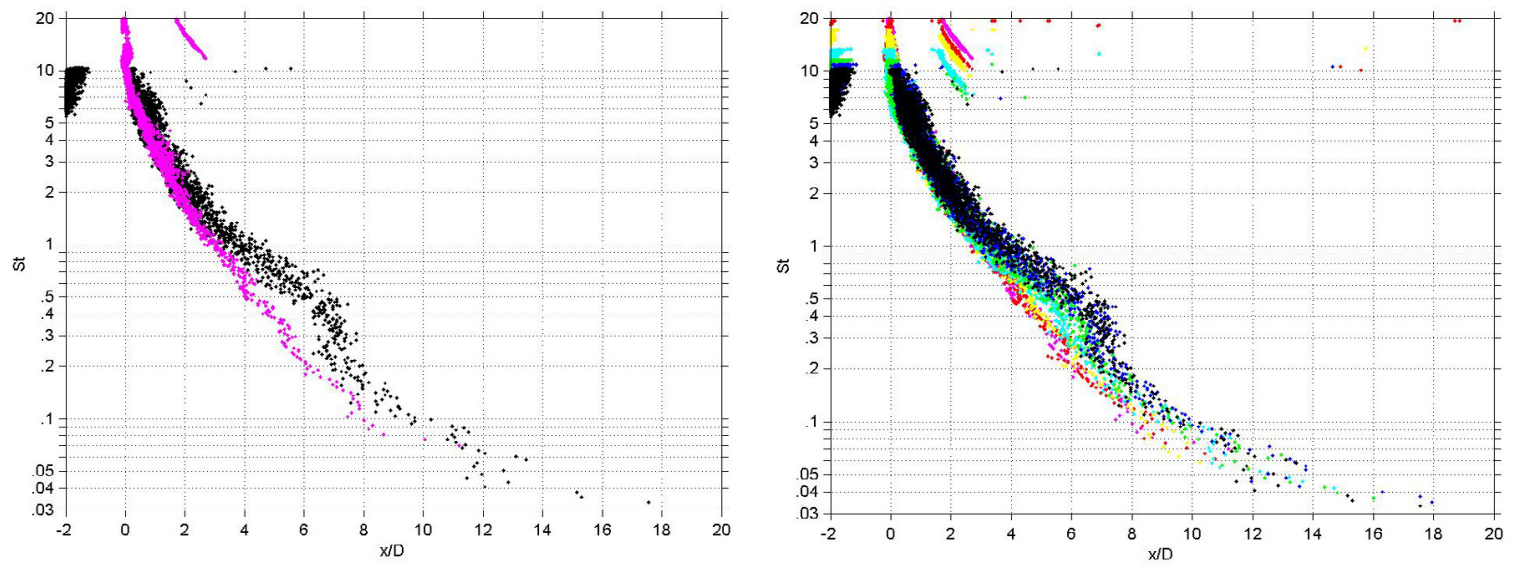

Figure 10.-Effect of acoustic Mach number on the peak locations of beamforming levels when the static temperature ratio is 2.27: (setpoint, $\mathrm{M}_{\mathrm{a}}, \mathrm{Ts}_{\mathrm{J}} / \mathrm{T}_{\mathrm{a}}$, color $)=(34,0.687,2.275$, magenta), $(35,0.788,2.269$, red), (36, 0.886, 2.271, yellow), (37, 1.15, 2.267, cyan), $(38,1.319,2.278$, green), $(139,1.396,2.268$, blue), and $(39,1.471,2.275$, black).
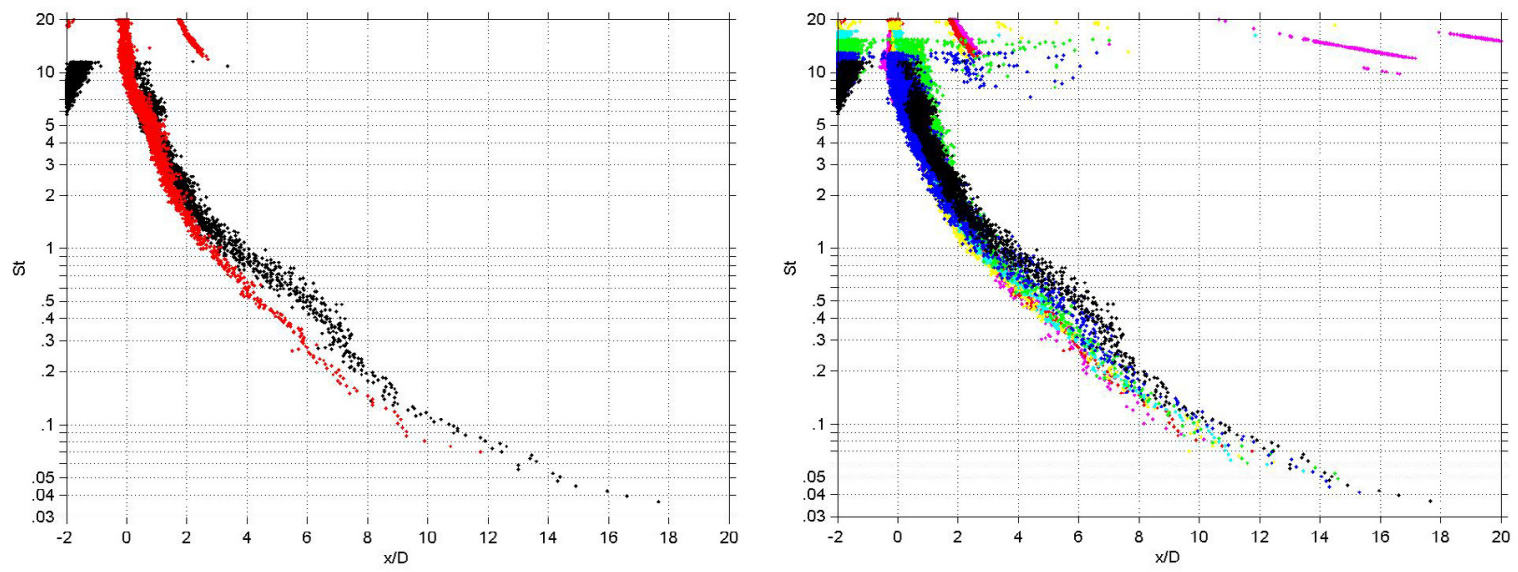

Figure 11.-Effect of acoustic Mach number on the peak locations of beamforming levels when the static temperature ratio is 1.765: (setpoint, $\mathrm{M}_{\mathrm{a}}, \mathrm{Ts}_{\mathrm{J}} / \mathrm{T}_{\mathrm{a}}$, color) $=(24,0.591,1.761$, magenta), $(25,0.693,1.769$, red), (26, 0.794, 1.763, yellow), (27, 0.89, 1.764, cyan), (135, 0.992, 1.77, green), (28, 1.178, 1.769, blue), and $(29,1.328,1.766$, black). 

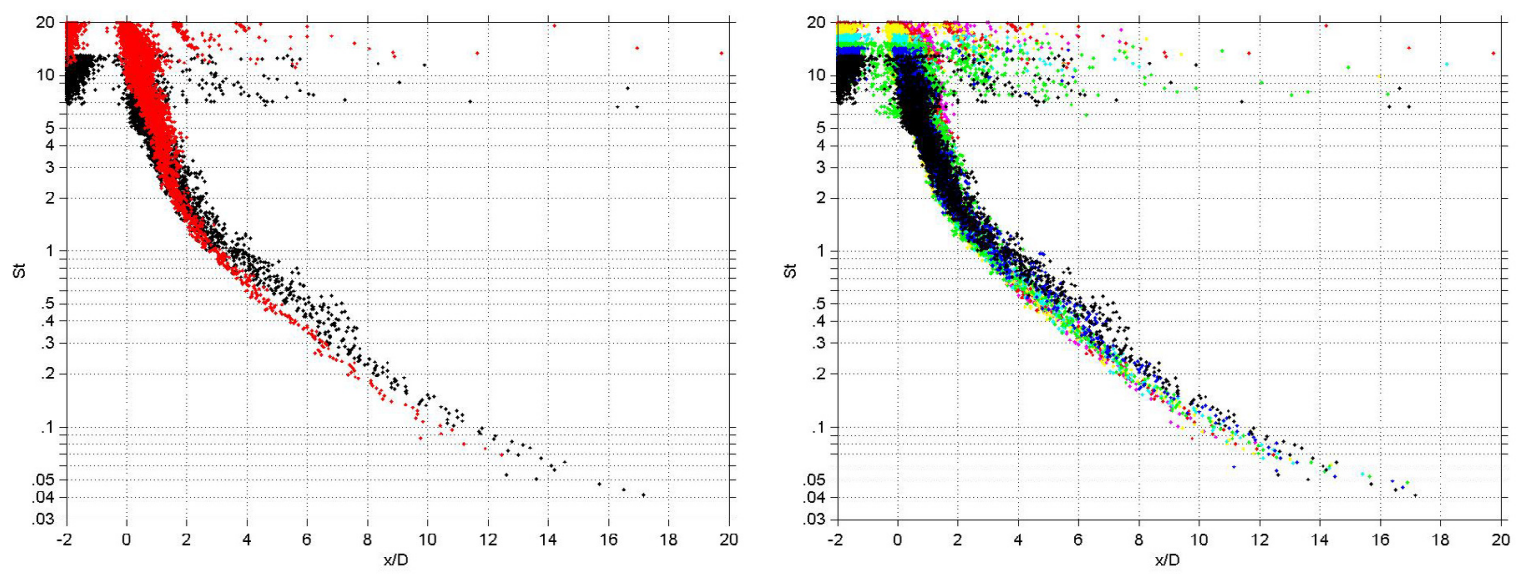

Figure 12.-Effect of acoustic Mach number on the peak locations of beamforming levels when the static temperature ratio is 1.429: (setpoint, $\mathrm{M}_{\mathrm{a}}, \mathrm{Ts}_{\mathrm{J}} / \mathrm{T}_{\mathrm{a}}$, color $)=(16,0.594,1.425$, magenta), $(17,0.694,1.428$, red), (18, 0.79, 1.433, yellow), (19, 0.896, 1.431, cyan), (134, 0.997, 1.429, green), (147, 1.06, 1.435, blue), and $(20,1.177,1.434$, black).

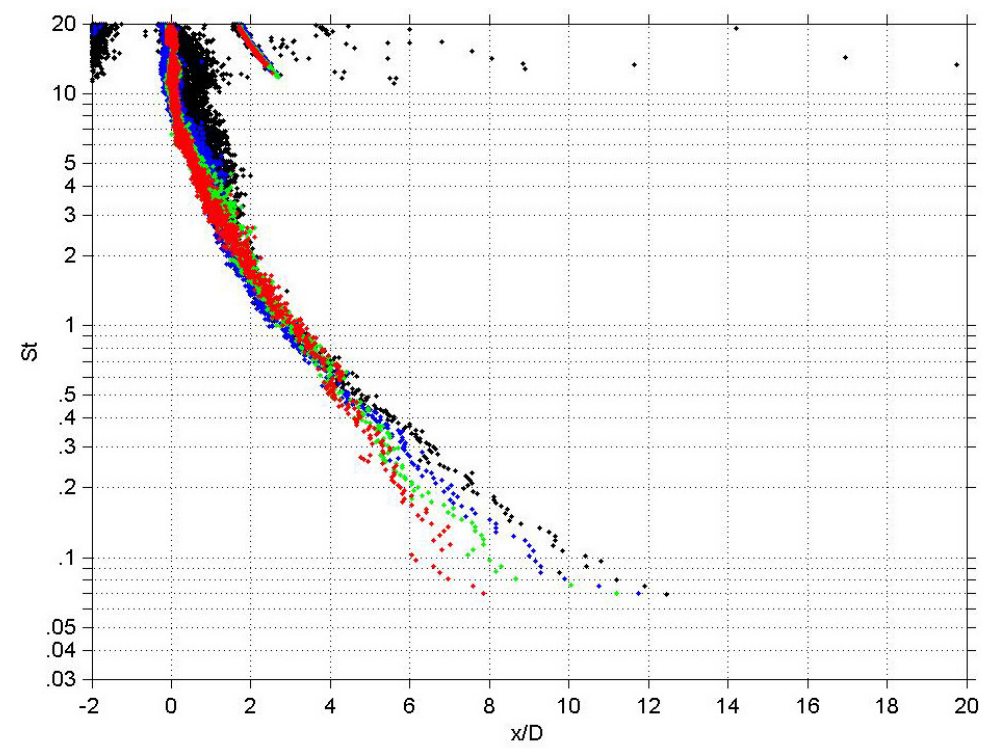

Figure 13.-Effect of static temperature ratio on the peak locations of beamforming levels when the acoustic Mach number is 0.7: (setpoint, $\mathrm{M}_{\mathrm{a}}, \mathrm{Ts}_{\mathrm{J}} / \mathrm{T}_{\mathrm{a}}$, color) $=(17,0.694,1.428$, black), $(25,0.693,1.769$, blue), $(34,0.687,2.275$, green), and $(44,0.689,2.712$, red $)$. 


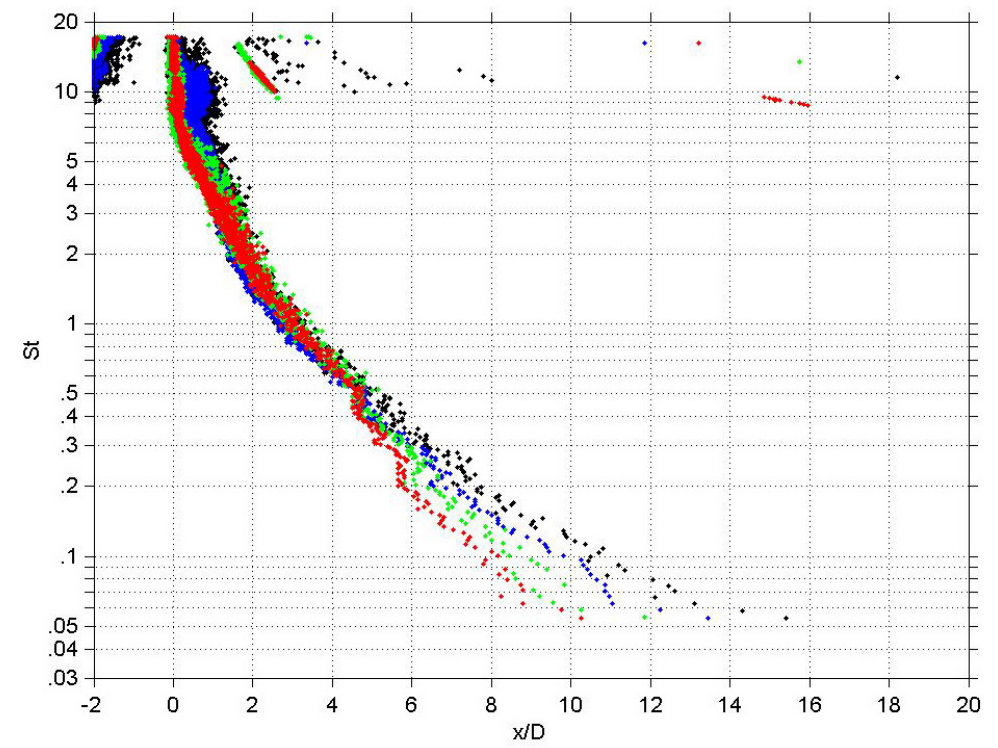

Figure 14.-Effect of static temperature ratio on the peak locations of beamforming levels when the acoustic Mach number is 0.9: (setpoint, $\mathrm{M}_{\mathrm{a}}, \mathrm{Ts}_{\mathrm{J}} / \mathrm{T}_{\mathrm{a}}$, color $)=(19,0.896,1.431$, black $),(27,0.89,1.764$, blue), $(36,0.886,2.271$, green), and $(46,0.888,2.699$, red).

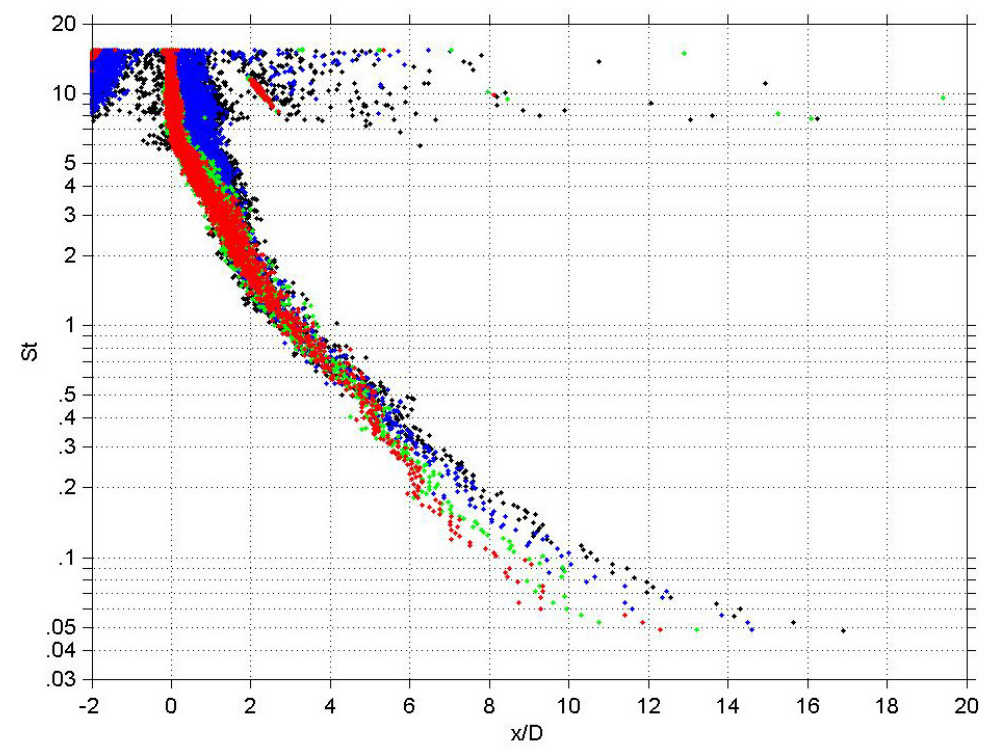

Figure 15.-Effect of static temperature ratio on the peak locations of beamforming levels when the acoustic Mach number is 1: (setpoint, $\mathrm{M}_{\mathrm{a}}, \mathrm{Ts}_{\mathrm{J}} / \mathrm{T}_{\mathrm{a}}$, color) $=(134,0.997,1.429$, black), (135, 0.992, 1.77, blue), $(136,0.987,2.272$, green), and (137, 0.992, 2.695, red). 


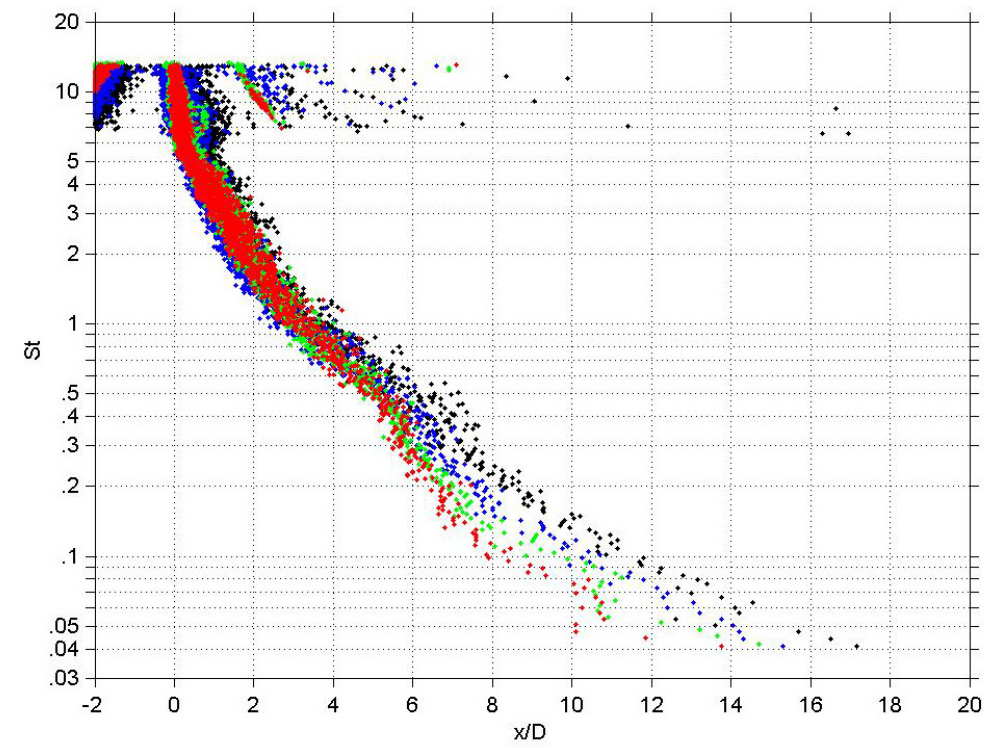

Figure 16.-Effect of static temperature ratio on the peak locations of beamforming levels when the acoustic Mach number is 1.185: (setpoint, $\mathrm{M}_{\mathrm{a}}, \mathrm{Ts}_{\mathrm{J}} / \mathrm{T}_{\mathrm{a}}$, color $)=(20,1.177,1.434$, black $),(28,1.178,1.769$, blue $)$, $(37,1.15,2.267$, green), and $(47,1.174,2.715$, red).

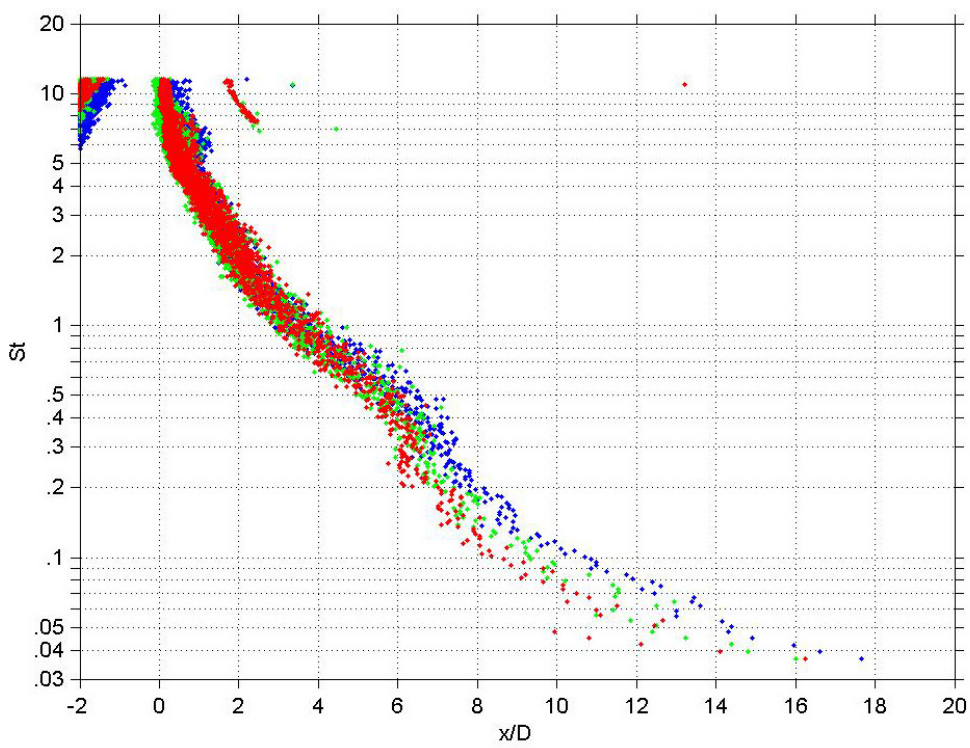

Figure 17.-Effect of static temperature ratio on the peak locations of beamforming levels when the acoustic Mach number is 1.33: (setpoint, $\mathrm{M}_{\mathrm{a}}, \mathrm{Ts}_{\mathrm{J}} / \mathrm{T}_{\mathrm{a}}$, color $)=(29,1.328,1.766$, blue $),(38,1.319,2.278$, green), and $(48,1.32,2.714$, red). 


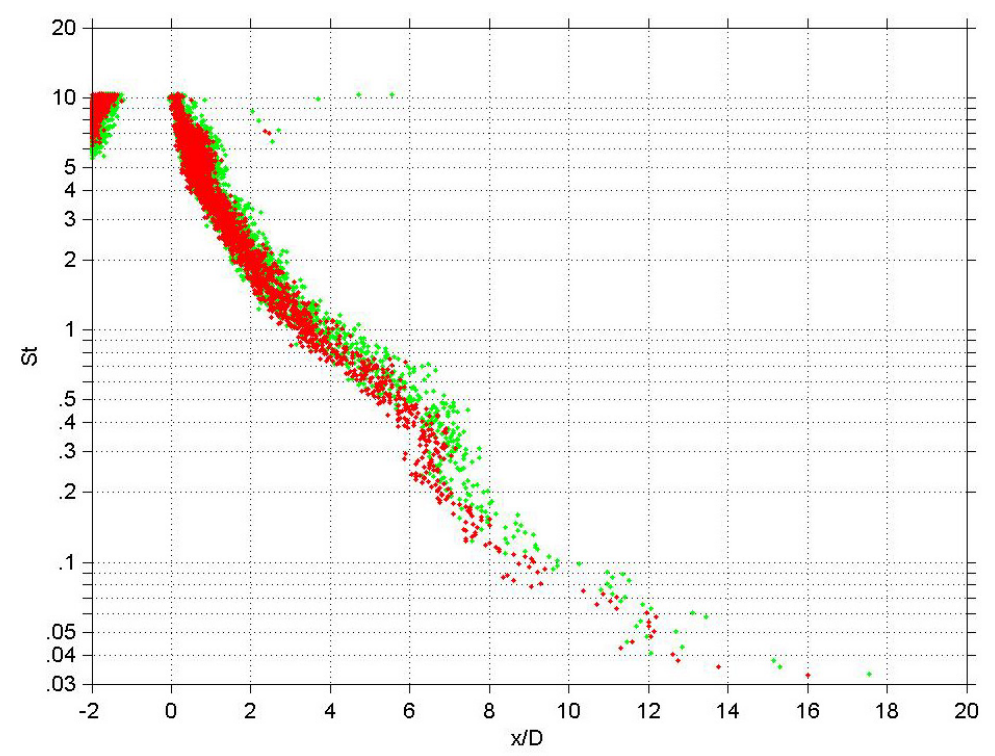

Figure 18.-Effect of static temperature ratio on the peak locations of beamforming levels when the acoustic Mach number is 1.48: $\left(\right.$ setpoint, $\mathrm{M}_{\mathrm{a}}, \mathrm{Ts}_{\mathrm{j}} / \mathrm{T}_{\mathrm{a}}$, color $)=(39,1.471,2.275$, green $)$, and $(49,1.474,2.696$, red).

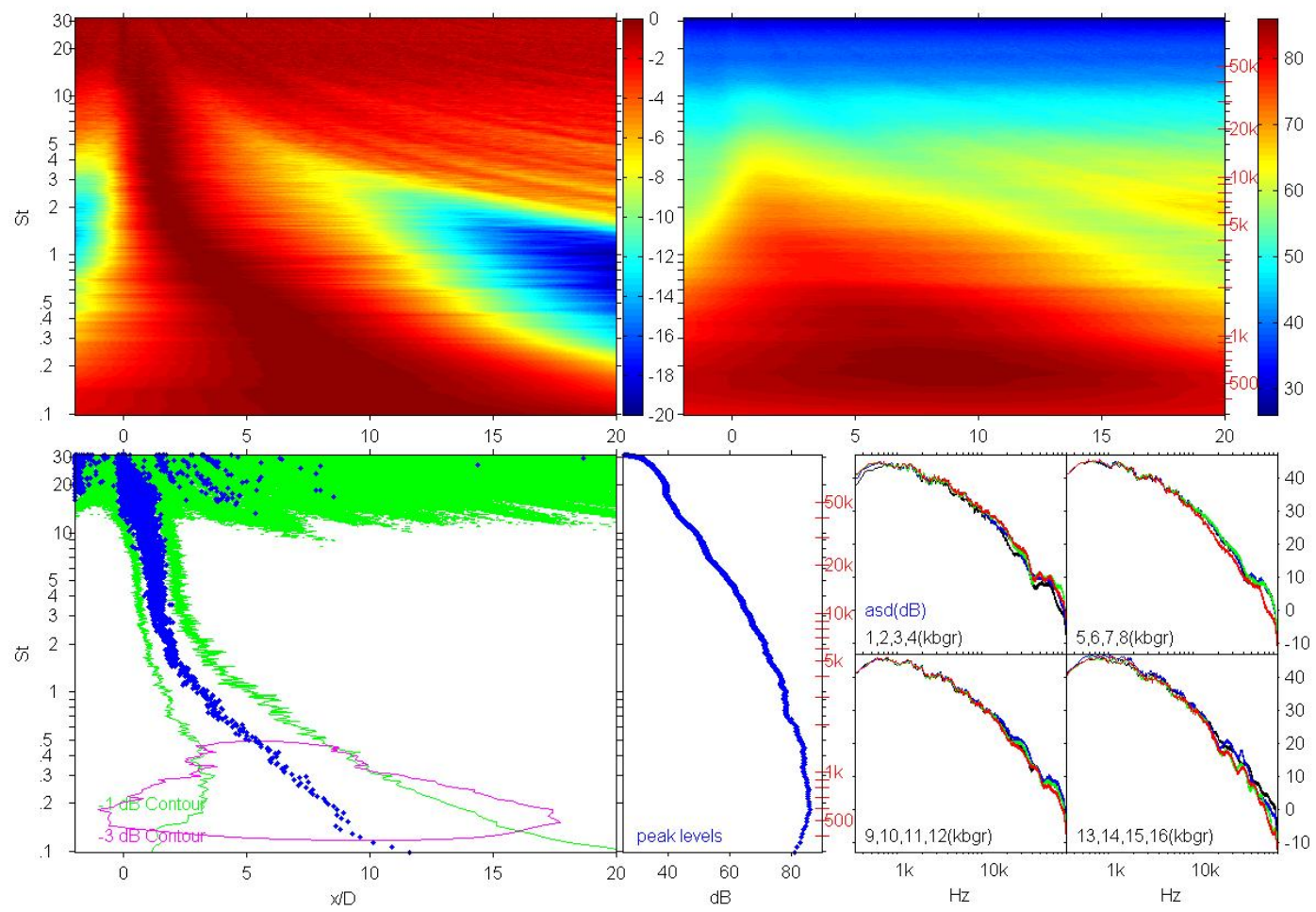

Figure 19.-Beamforming results of a cold jet at the set point 3: $\mathrm{M}_{\mathrm{a}}=0.491$ and $\mathrm{Ts}_{\mathrm{J}} / \mathrm{T}_{\mathrm{a}}=0.967$. 


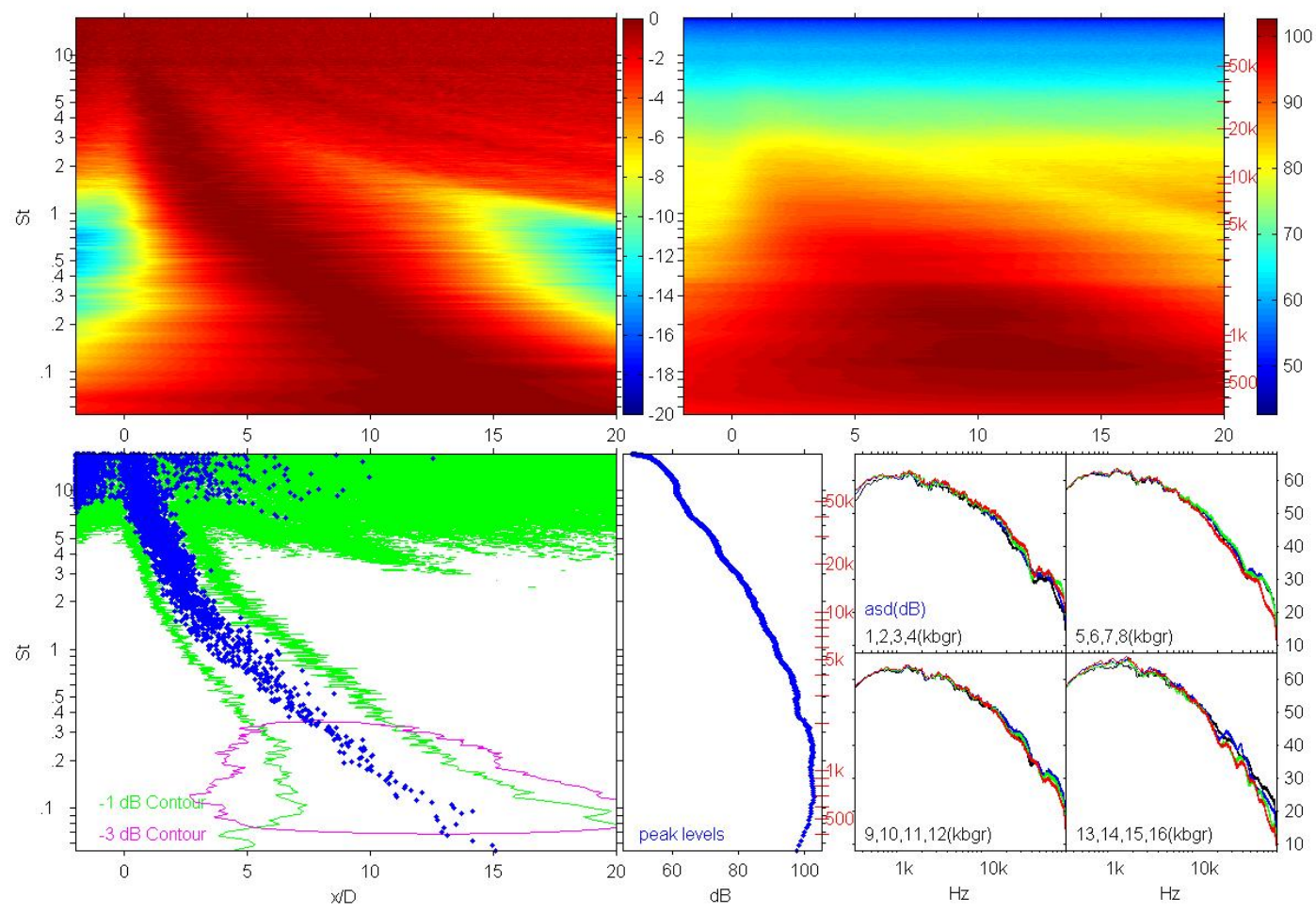

Figure 20.-Beamforming results of a cold jet at the set point 7: $\mathrm{M}_{\mathrm{a}}=0.891$ and $\mathrm{Ts}_{\mathrm{J}} / \mathrm{T}_{\mathrm{a}}=0.84$.
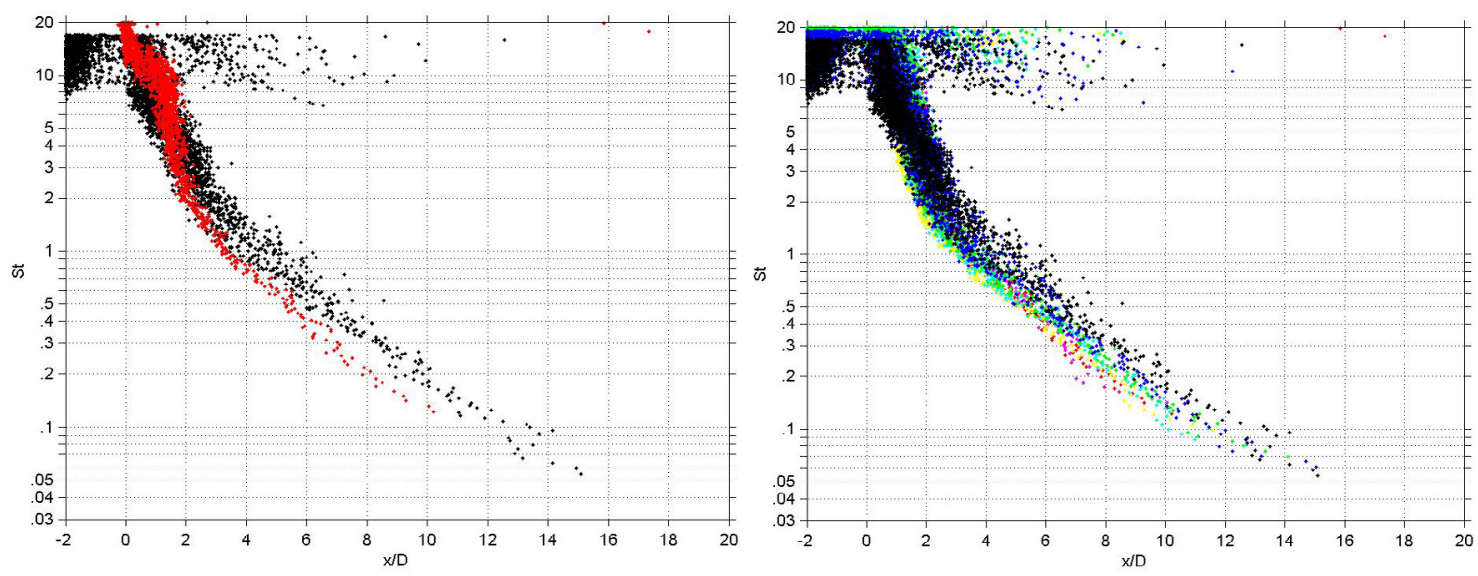

Figure 21.-Effect of acoustic Mach number on the peak locations of beamforming levels of cold jets: (setpoint, $\mathrm{M}_{\mathrm{a}}, \mathrm{Ts}_{\mathrm{J}} / \mathrm{T}_{\mathrm{a}}$, color $)=(1,0.343,0.999$, magenta $),(2,0.394,0.989$, red $),(3,0.491,0.967$, yellow $)$, $(4,0.596,0.941$, cyan $),(5,0.696,0.91$, green $),(6,0.795,0.878$, blue $)$, and $(7,0.891,0.84$, black $)$. 


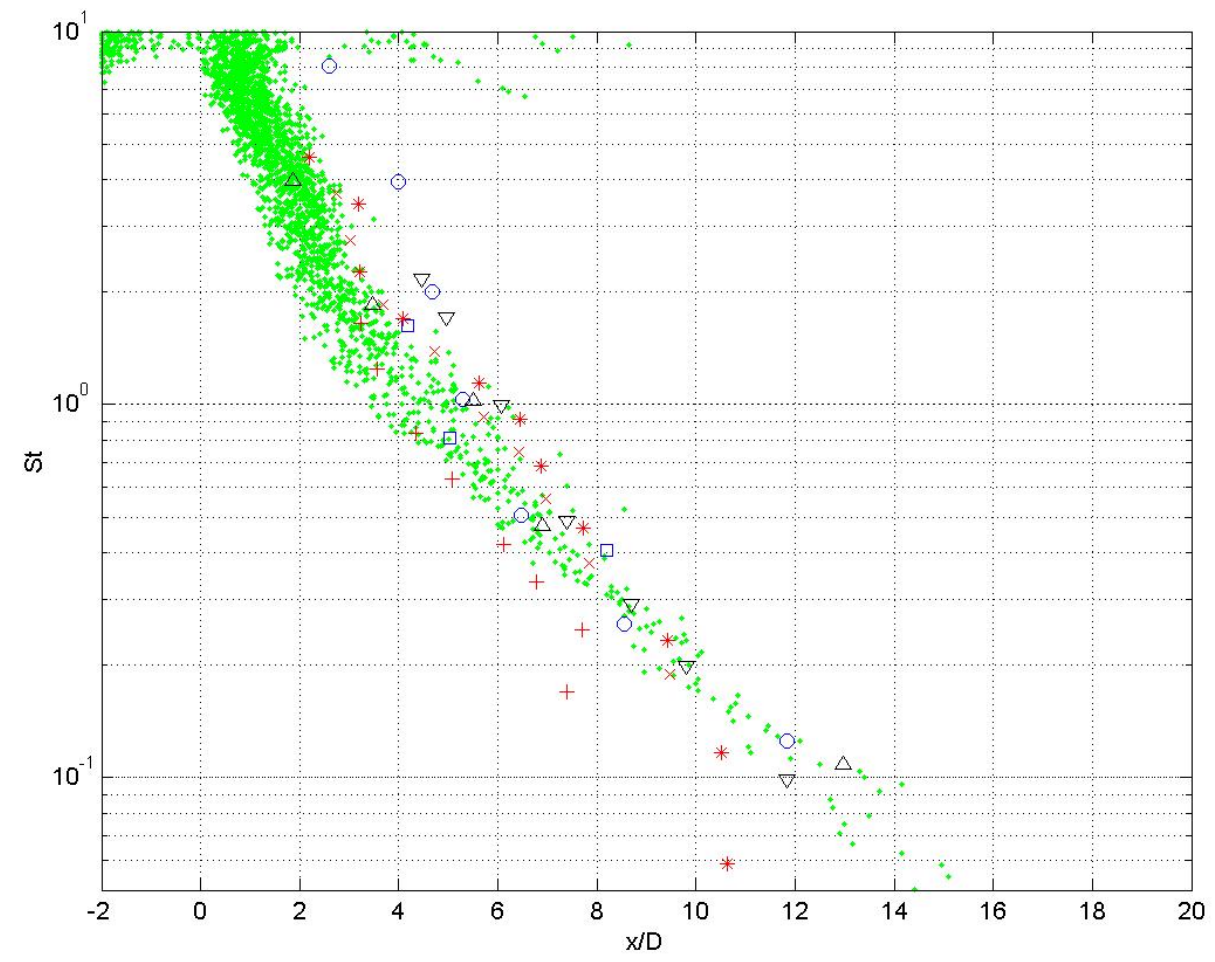

Figure 22.-Comparison with other source location techniques. Green dot: current phased array method at set point 7, blue square: Chu, et al. (1972), blue circle: Grosche (1973), black triangle (down and up): Fisher, et al. (1976), red +, x, *: Ahuja, et al. (1998).

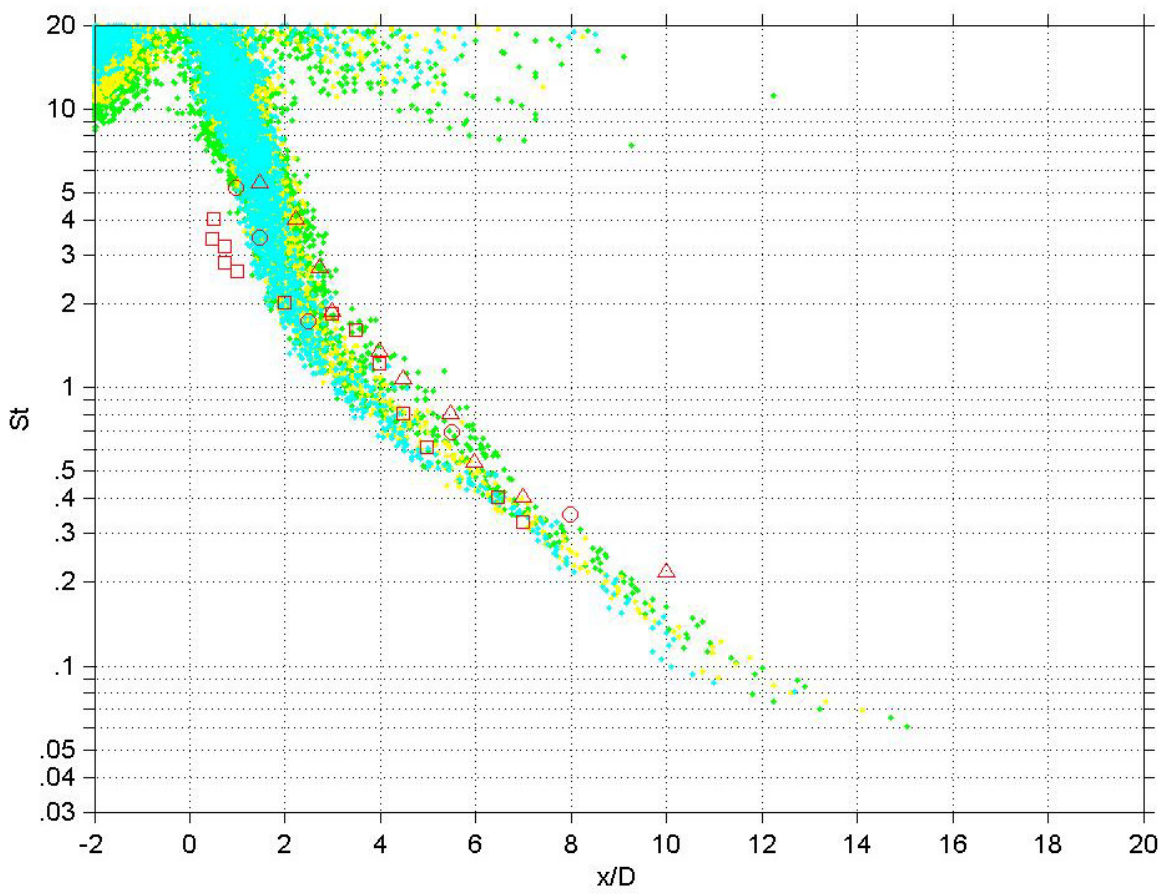

Figure 23. - Comparison of the peak source locations of cold jets. Current data: (setpoint, $\mathrm{M}_{\mathrm{J}}, \mathrm{Ts}_{\mathrm{J}} / \mathrm{T}_{\mathrm{a}}$, symbol) = $(4,0.615,0.941$, cyan dots $),(5,0.73,0.91$, yellow dots), and $(6,0.849,0.878$, green dots). Peak locations by Narayanan, et al. (2002) when $\mathrm{M}_{\mathrm{J}}=0.6$ (red square), 0.7 (red circle), and 0.9 (red triangle) and the jet exit temperature is $80^{\circ} \mathrm{F}$. 


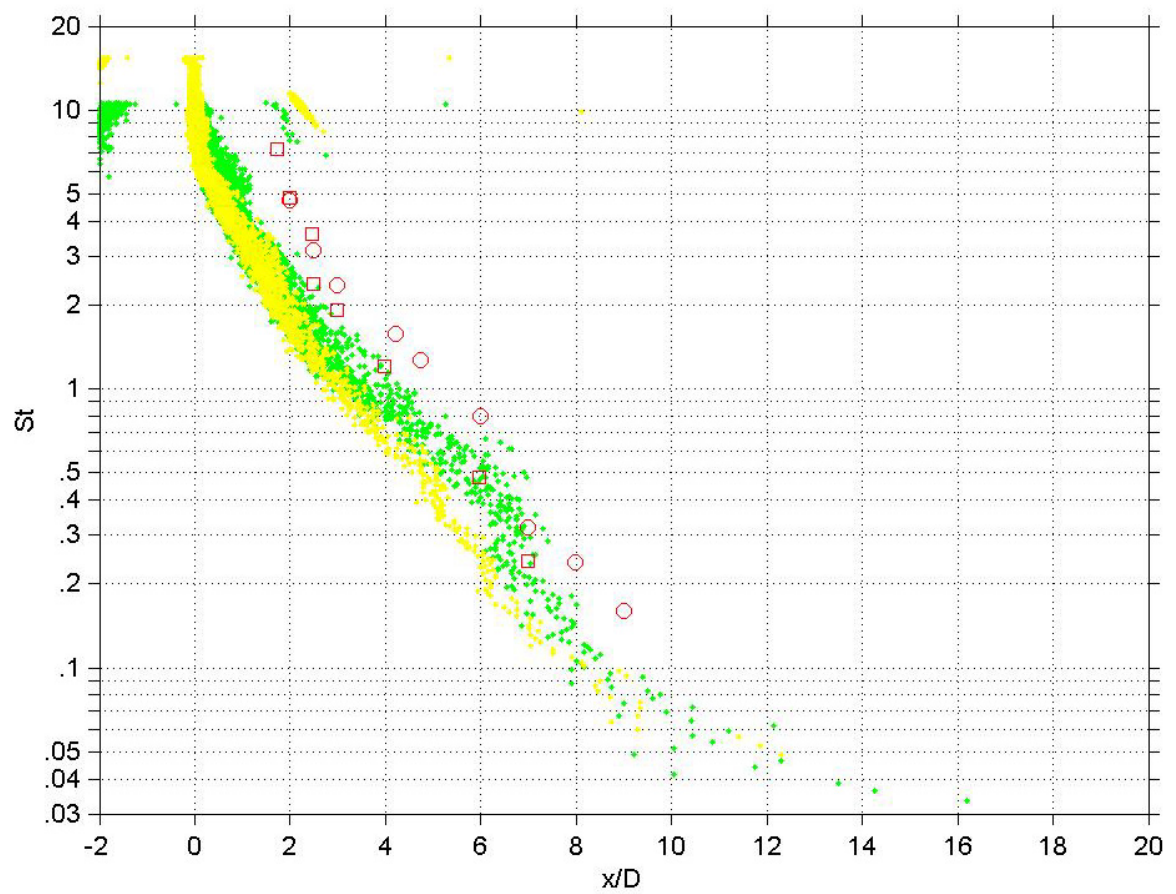

Figure 24. - Comparison of the peak source locations of hot jets. Current data: (setpoint, $\mathrm{M}_{\mathrm{J}}, \mathrm{Ts}_{\mathrm{J}} / \mathrm{T}_{\mathrm{a}}$, symbol) = $(137,0.613,2.695$, yellow dots), and $(150,0.887,2.718$, green dots). Peak locations by Narayanan, et al. (2002) when $\mathrm{M}_{\mathrm{J}}=0.6$ (red square), and 0.9 (red circle) and the jet exit temperature is $1000^{\circ} \mathrm{F}$. 


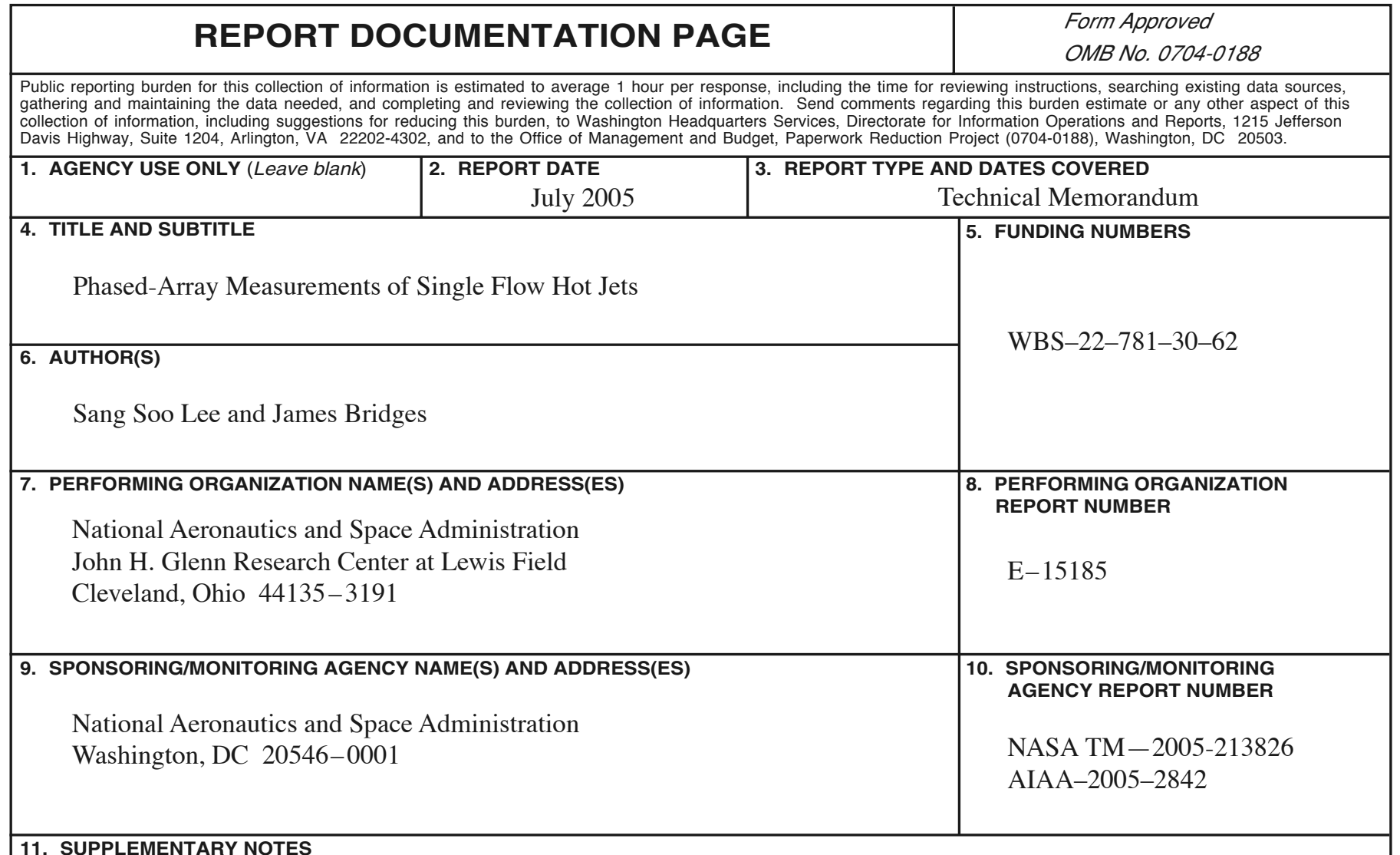

\section{SUPPLEMENTARY NOTES}

Prepared for the 11th Aeroacoustics Conference cosponsored by the American Institute of Aeronautics and Astronautics and the Confederation of European Aerospace Societies, Monterey, California, May 23-25, 2005. Sang Soo Lee, QSS Group, Inc., 21000 Brookpark Road, Cleveland, Ohio 44135; and James Bridges, NASA Glenn Research Center. Responsible person, Sang Soo Lee, organization code RTA, 216-977-1378.

\begin{tabular}{|l|l|l|l|l|}
\hline 12a. DISTRIBUTION/AVAILABILITY STATEMENT & DISTRIBUTION CODE
\end{tabular}

Unclassified - Unlimited

Subject Categories: 07 and 34

Available electronically at http://gltrs.grc.nasa.gov

This publication is available from the NASA Center for AeroSpace Information, 301-621-0390.

13. ABSTRACT (Maximum 200 words)

A 16 microphone phased-array system has been successfully applied to measure jet noise source distributions. In this study, a round convergent nozzle was tested at various hot and cold flow conditions: acoustic Mach numbers are between 0.35 and 1.6 and static temperature ratios are varied from cold to 2.7. The classical beamforming method was applied on narrowband frequencies. From the measured source distributions locations of peak strength were tracked and found to be very consistent between adjacent narrowband frequencies. In low speed heated and unheated jets, the peak source locations vary smoothly from the nozzle exit to downstream as the frequency is decreased. When the static temperature ratio was kept constant, the peak source position moved downstream with increasing acoustic Mach number for the Strouhal numbers smaller than about 1.5. It was also noted that the peak source locations of low frequencies occur farther downstream than the end of potential core.

\section{SUBJECT TERMS}

Phased array; Aeroacoustics jet; Jet noise; Hot jet; Jet noise source location

15. NUMBER OF PAGES

23

16. PRICE CODE

20. LIMITATION OF ABSTRACT

\begin{tabular}{c|c|c}
$\begin{array}{l}\text { 17. SECURITY CLASSIFICATION } \\
\text { OF REPORT } \\
\text { Unclassified }\end{array}$ & $\begin{array}{c}\text { 18. SECURITY CLASSIFICATION } \\
\text { OF THIS PAGE } \\
\text { Unclassified }\end{array}$ & $\begin{array}{c}\text { 19. SECURITY CLASSIFICATION } \\
\text { OF ABSTRACT } \\
\text { Unclassified }\end{array}$
\end{tabular}

NSN 7540-01-280-5500
Standard Form 298 (Rev. 2-89)

Prescribed by ANSI Std. Z39-18 298-102 

